\title{
Allergic $T_{H} 2$ Response Governed by B-Cell Lymphoma 6 Function in Naturally Occurring Memory Phenotype CD4 ${ }^{+}$T Cells
}

\section{OPEN ACCESS}

Edited by:

Keiko Ozato,

National Institutes of Health $(\mathrm{NIH})$,

United States

Reviewed by:

Jinfang Zhu,

National Institute of Allergy and Infectious Diseases (NIH),

United States

Christopher E. Rudd,

Université de Montréal, Canada

${ }^{*}$ Correspondence:

Masafumi Arima

masaa@dokkyomed.ac.jp

Specialty section:

This article was submitted

to T Cell Biology,

a section of the journal

Frontiers in Immunology

Received: 11 November 2017

Accepted: 26 March 2018

Published: 10 April 2018

Citation:

Ogasawara T, Kohashi Y, Ikari J, Taniguchi T, Tsuruoka N, WatanabeTakano H, Fujimura L, Sakamoto A, Hatano M, Hirata H, Fukushima Y,

Fukuda T, Kurasawa K, Tatsumi $K$,

Tokuhisa T and Arima M (2018)

Allergic $T_{H} 2$ Response Governed by

B-Cell Lymphoma 6 Function in

Naturally Occurring Memory

Phenotype CD4+ $T$ Cells.

Front. Immunol. 9:750.

doi: 10.3389/fimmu.2018.00750
Takashi Ogasawara', Yuko Kohashi' ${ }^{2}$, Jun Ikari', Toshibumi Taniguchi', Nobuhide Tsuruoka ${ }^{3}$, Haruko Watanabe-Takano', Lisa Fujimura', Akemi Sakamoto², Masahiko Hatano², Hirokuni Hirata ${ }^{5}$, Yasutsugu Fukushima ${ }^{5}$, Takeshi Fukuda 6 , Kazuhiro Kurasawa ${ }^{7}$, Koichiro Tatsumi', Takeshi Tokuhisa ${ }^{8}$ and Masafumi Arima ${ }^{2,7 *}$

${ }^{1}$ Department of Respirology (B2), Chiba University Graduate School of Medicine, Chiba, Japan, ${ }^{2}$ Department of Biomedical Science (M14), Chiba University Graduate School of Medicine, Chiba, Japan, ${ }^{3}$ Department of Reproductive Medicine (G4), Chiba University Graduate School of Medicine, Chiba, Japan, ${ }^{4}$ Biomedical Research Center, Chiba University, Chiba, Japan, ${ }^{5}$ Department of Respiratory Medicine and Clinical Immunology, Dokkyo Medical University Koshigaya Hospital, Koshigaya, Japan, ${ }^{6}$ Department of Pulmonary Medicine and Clinical Immunology, Dokkyo Medical University School of Medicine, Mibu, Japan, ${ }^{7}$ Department of Rheumatology, Dokkyo Medical University School of Medicine, Mibu, Japan, ${ }^{8}$ Department of Developmental Genetics, Chiba University Graduate School of Medicine, Chiba, Japan

Transcriptional repressor B-cell lymphoma 6 (Bcl6) appears to regulate $T_{H} 2$ immune responses in allergies, but its precise role is unclear. We previously reported that Bcl6 suppressed IL-4 production in naïve $\mathrm{CD}^{+}{ }^{+} \mathrm{T}$ cell-derived memory $\mathrm{T}_{\mathrm{H}} 2$ cells. To investigate Bcl6 function in allergic responses in naturally occurring memory phenotype $C D 4^{+} \mathrm{T}$ (MPT) cells and their derived $\mathrm{T}_{\mathrm{H}} 2\left(\mathrm{MPT}_{\mathrm{H}} 2\right)$ cells, Bc/6-manipulated mice, highly conserved intron enhancer (hclE)-deficient mice, and reporter mice for conserved noncoding sequence 2 (CNS2) 3' distal enhancer region were used to elucidate Bcl6 function in MPT cells. The molecular mechanisms of Bcl6-mediated $\mathrm{T}_{\mathrm{H}} 2$ cytokine gene regulation were elucidated using cellular and molecular approaches. Bcl6 function in MPT cells was determined using adoptive transfer to naïve mice, which were assessed for allergic airway inflammation. Bcl6 suppressed IL-4 production in MPT and MPT 2 cells by suppressing CNS2 enhancer activity. Bcl6 downregulated //4 expression in MPT 2 cells, but not MPT cells, by suppressing hclE activity. The inhibitory functions of Bcl6 in MPT and MPTH2 cells attenuated allergic responses. Bcl6 is a critical regulator of IL-4 production by MPT and $\mathrm{MPT}_{\mathrm{H}} 2$ cells in $\mathrm{T}_{\mathrm{H}} 2$ immune responses related to the pathogenesis of allergies.

\section{Keywords: B-cell lymphoma 6, naturally occurring memory phenotype T cells, allergy, $\mathrm{T}_{\mathrm{H}} 2$ cells, asthma}

\footnotetext{
Abbreviations: Abs, antibodies; APC, antigen-presenting cell; BAL, Bronchoalveolar lavage; BALF, Bronchoalveolar lavage fluid; Bcl6, B-cell lymphoma 6; BS, binding sequence; ChIP, chromatin immunoprecipitation; CNS, conserved noncoding sequence; DC, dendritic cell; EGFP, enhanced green fluorescent protein; FACS, fluorescence-activated cell sorting; GFP, green fluorescent protein; hcIE, highly conserved intron enhancer; HS, DNase hypersensitive site; KO, knockout; LCR, locus control region; LTR, long terminal repeat; mAbs, monoclonal antibodies; MFI, mean fluorescence intensity; MPT cell, memory pheno-

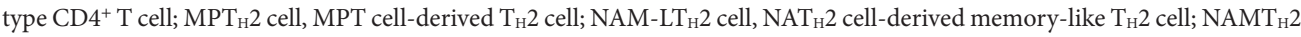
cell, $\mathrm{NAT}_{\mathrm{H}} 2$ cell-derived memory cell; $\mathrm{NAT}_{\mathrm{H}} 2$ cell, naïve $\mathrm{CD} 4{ }^{+} \mathrm{T}$ cell-derived $\mathrm{T}_{\mathrm{H}} 2$ cell; OVA, ovalbumin; PCR, polymerase chain reaction; STAT, signal transducer and activator of transcription; $\mathrm{TCR}$, $\mathrm{T}$ cell receptor; $\mathrm{T}_{\mathrm{FH}}$ cell, $\mathrm{T}$ follicular helper cell; TG, transgenic; WT, wild-type.
} 


\section{INTRODUCTION}

Allergic asthma is an inflammatory airway disorder mediated by $\mathrm{T}_{\mathrm{H}} 2$ cells, which produce various effector cytokines (IL-4, IL-5, and IL-13) $(1,2)$. IL-4 induces signal transducer and activator of transcription (STAT) 6 phosphorylation, causing the protein to translocate to the nucleus, where it induces the expression of Gata3 $(3,4)$, a key regulator of $\mathrm{T}_{\mathrm{H}} 2$ cell differentiation. GATA3 facilitates $I l 4, I l 5$, and $I l 13$ transcription in $\mathrm{T}_{\mathrm{H}} 2$ cells $(3,4)$. In mouse and human allergies, IL- 4 initiates $\mathrm{T}_{\mathrm{H}} 2$ responses and IgE isotype class switching, whereas IL- 5 and IL-13 are important for eosinophil infiltration/activation and increased airway hyperreactivity in allergic asthma $(1,2)$.

The proto-oncogene product B-cell lymphoma 6 (Bcl6) is a sequence-specific transcriptional repressor (5-9). Tissue hypereosinophilia occurs with increased IL-4, IL-5, and IL-13 production in B-cell lymphoma $6(\mathrm{Bcl} 6)$-knockout $(\mathrm{KO})$ mice, suggesting that Bcl6 participates in allergy pathogenesis and that it may be important for reducing $\mathrm{T}_{\mathrm{H}} 2$ immune responses. However, the $\mathrm{T}$ cell-intrinsic function of $\mathrm{Bcl} 6$ in $\mathrm{T}_{\mathrm{H}} 2$ cell responses remains unclear. Bcl6-binding DNA sequences resemble STAT protein-bound motifs (10), indicating that Bcl6 may repress $\mathrm{T}_{\mathrm{H}} 2$ cytokine expression by competitively inhibiting the binding of STAT factors to GAS sites in target genes $(5,11-13)$, including $\mathrm{T}_{\mathrm{H}} 2$ cytokine gene loci (14). We previously identified Bcl6/STAT-binding sequences (BSs) (15) in CNS1 (BS1), IL-4 promoter region (BS2), and DNase hypersensitive site 2 (HS2) (BS3, BS4) and HS3 (BS5, BS6) in intron two and the $3^{\prime}$ region of CNS2 (BS7) in the Il4 locus; BSIL5 sequences in the Il5 locus (14); and BSIL13 sequences in the Il13 locus. We, furthermore, reported that Bcl6 repressed Il4 and Il5 expression by binding to genomic DNA in naïve $\mathrm{CD} 4^{+} \mathrm{T}$ cell-derived memory (NAM) $\mathrm{T}_{\mathrm{H}} 2$ cells $(14,15)$, identifying $\mathrm{Bcl} 6$ as a critical regulator of $\mathrm{T}_{\mathrm{H}} 2$ cytokine production in memory $\mathrm{CD} 4^{+} \mathrm{T}$ cells in addition to its role in the maintenance and survival of the cells (15-17). Conversely, $\mathrm{T}$ follicular helper $\left(\mathrm{T}_{\mathrm{FH}}\right)$ cell differentiation may result from Bcl6-mediated suppression of the differentiation of other $\mathrm{T}_{\mathrm{H}}$ cell lineages in vivo (18-20). Thus, the role of Bcl6 in the regulation of $\mathrm{T}_{\mathrm{H}} 2$ cytokine production in pathophysiological settings remains unclear. We focused on a $\mathrm{CD} 4^{+} \mathrm{T}$ cell subset, namely, naturally occurring memory phenotype $\mathrm{CD} 4^{+} \mathrm{T}(\mathrm{MPT})$ cells (21-27). These are derived from $\mathrm{CD} 4^{+} \mathrm{T}$ cells that naturally exhibit memory cell markers (CD44 high $\mathrm{CD} 25^{-} \mathrm{CD} 49 \mathrm{~b}^{-}$) without antigen stimulation, rather than from memory $\mathrm{CD}^{+} \mathrm{T}$ cells differentiated from naïve $\mathrm{CD} 4^{+} \mathrm{T}$ cells after antigen stimulation. A small subset of MPT cells and their derived $\mathrm{MPT}_{\mathrm{H}} 2$ cell populations, but not naïve $\mathrm{CD} 4^{+} \mathrm{T}$ cell-derived $\mathrm{T}_{\mathrm{H}} 2$ cells $\left(\mathrm{NAT}_{\mathrm{H}} 2\right.$ cells), have an active conserved noncoding sequence 2 (CNS2) $3^{\prime}$ distal enhancer region in the Il4 locus similar to that in natural killer $\mathrm{T}$ cells, producing IL-4 without $\mathrm{T}$ cell receptor (TCR)-mediated stimulation (28). CNS2-active MPT cells are candidate cells that initially produce IL- 4 to promote $\mathrm{T}_{\mathrm{H}} 2$ cell differentiation, and thus, they may be involved in allergy pathogenesis, although the mechanisms remain unclear. Because Bcl6 expression is extremely high in CNS2-active MPT cells (29), we hypothesized that Bcl6 regulates allergen-mediated MPT cell activation in $\mathrm{T}_{\mathrm{H}} 2$ cell-dependent allergies.

\section{MATERIALS AND METHODS}

\section{Antibodies (Abs) and Reagents}

Allophycocyanin-conjugated anti-CD4 monoclonal antibody (mAb, GK1.5), anti-IL-4 mAb (11B11), anti-IFN- $\gamma$ mAb (R46A2), anti-CD62L mAb (MEL-14), anti-CD44 mAb (IM7), PE-conjugated anti-IL-4 mAb (BVD4-1D11), PE-conjugated KJ1-26 (anti-clonotypic mAb for DO11.10 TCR, KJ1-26), anti-CD11c mAb (HL3), unconjugated anti-IL-4 mAb (11B11), anti-IL-12 mAb (C17.8), anti-IFN-mAb (R4-6A2), anti-CD44 mAb (IM7), FITC-conjugated anti-CD49b mAb (DX5), and PerCP-conjugated anti-CD4 $\mathrm{mAb}$ (GK1.5) were purchased from BD Bioscience. Anti-STAT5 Abs (C-17), anti-STAT6 Abs (N-20), anti-Bcl6 Abs (N-3), anti-tubulin Abs (H-235), and normal rabbit IgG were purchased from Santa Cruz Biotechnology. FITCconjugated anti-T1/ST2 (IL-33R) $\mathrm{mAb}$ (DJ8) was purchased from MD Bioproducts. Mouse rIL-2, rIL-4, rIL-7, rIL-12, and rIL-33 were purchased from PeproTech. Anti-CD3e mAbs (145-2C11) were purchased from Cedar Lane. Anti-CD28 mAbs (PV-1) were purchased from Southern Biotechnology. The ovalbumin (OVA) peptide (Loh15: residues 323-339; ISQAVHAAHAEINEAGR) was synthesized by BEX Co. Ltd. (Tokyo, Japan). The Bcl6 inhibitory peptide was synthesized by Scrum Inc. (Tokyo, Japan).

\section{Animals}

$B c l 6$-transgenic (TG) mice with exogenous Bcl6 under Lck proximal promoter control $(17,30), B c l 6-\mathrm{KO}$ mice (31), and highly conserved intron enhancer (hcIE)-KO mice on a BALB/c background (Japan SLC) were described previously (15). CNS2-green fluorescent protein (GFP)-TG mice were gifted by Dr. Masato Kubo (28). Some Bcl6-TG, Bcl6-KO, and hcIE-KO mice were crossed with OVA-specific TCR $\alpha \beta$ (DO11.10) and/or CNS2-GFP-TG mice. All mice were used at 8-12 weeks of age.

\section{CD4 $^{+} \mathrm{T}$ Cell Purification and $\mathrm{T}_{\mathrm{H}}$ Cell Induction}

Naïve CD44 ${ }^{\text {low }} \mathrm{CD} 2 \mathrm{~L}^{+} \mathrm{CD} 4^{+} \mathrm{T}$ cells, $\mathrm{CD} 44^{\text {high }} \mathrm{CD} 2 \mathrm{~L}^{-} \mathrm{CD} 4^{+}$ MPT cells, transferred $\mathrm{T}$ cells, dendritic cells (DCs), and T celldeleted splenocytes were isolated from murine spleens using a cell sorter (FACSVantage, BD Biosciences). Sorted T cells $\left(2 \times 10^{5}\right.$ cells $\left./ \mathrm{mL}\right)$ from DO11.10 background mice were stimulated with OVA peptides (Loh15) $(1 \mu \mathrm{g} / \mathrm{mL})$ plus irradiated or CD11 $C^{+}$DCs $\left(4 \times 10^{4}\right.$ cells $\left./ \mathrm{mL}\right)$ or splenocytes $\left(1 \times 10^{6}\right.$ cells/ $\mathrm{mL}$ ), depleted of $\mathrm{CD}^{+}$and $\mathrm{CD} 8^{+} \mathrm{T}$ cells, and used as antigenpresenting cells (APCs) in the presence of rIL-2 $(25 \mathrm{U} / \mathrm{mL})\left(\mathrm{T}_{\mathrm{H}} 0\right.$ condition). In addition to primary TCR-mediated stimulation with OVA, stimulation with soluble anti-CD3 $(2 \mu \mathrm{g} / \mathrm{mL})$ and anti-CD28 mAbs $(2 \mu \mathrm{g} / \mathrm{mL})$ was employed for some experiments. For $\mathrm{T}_{\mathrm{H}} 1$ or $\mathrm{T}_{\mathrm{H}} 2$ polarization, cells were cultured in the presence of rIL-12 (100 U/mL)/anti-IL-4 mAb $(5 \mu \mathrm{g} / \mathrm{mL})$ or rIL-4 $(1,000 \mathrm{U} /$ $\mathrm{mL}) /$ anti-IL-12 $\mathrm{mAb}(10 \mu \mathrm{g} / \mathrm{mL})$, as previously described (15). In some experiments, anti-IL-4 mAbs or anti-IFN- $\gamma$ mAbs were added to the $\mathrm{T}_{\mathrm{H}} 0$ condition cultures. On days 3 and 5 , activated naïve T cells and MPT cells were stimulated with rIL-2 (25 U/ $\mathrm{mL})$ and rIL-7 $(10 \mathrm{U} / \mathrm{mL})$ following primary stimulation. $\mathrm{NAT}_{\mathrm{H}} 2$ cells were further cultured with IL-7 for 21 days to yield $\mathrm{NAT}_{\mathrm{H}} 2$ 
cell-derived memory-like $\mathrm{T}_{\mathrm{H}} 2\left(\mathrm{NAM}-\mathrm{LT}_{\mathrm{H}} 2\right)$ cells, which have a functional phenotype similar to $\mathrm{NAT}_{\mathrm{H}} 2$ cell-derived memory $\left(\mathrm{NAMT}_{\mathrm{H}} 2\right)$ cells in vivo (15). Some MPT cells were cultured in the presence of IL-33 (0-100 ng/mL) with or without IL-7 for the appropriate times as shown in each experiment prior to analysis of chromatin immunoprecipitation (ChIP) assays and the effect of TCR stimulation on cytokine production.

\section{Fluorescence-Activated Cell Sorting (FACS) Analysis}

As previously described $(15,17)$, T cells with or without $8 \mathrm{~h}$ of restimulation were treated with monensin $(2 \mu \mathrm{M})$ for the last $3 \mathrm{~h}$, followed by staining with an appropriate combination of FITCconjugated anti-KJ1-26, APC-conjugated anti-CD44, and PerCPconjugated anti-CD4 mAbs. For staining, cells were washed once with FACS buffer (PBS with $3 \%$ fetal calf serum and $0.1 \%$ sodium azide) and then permeabilized with Perm2 (BD Biosciences) for $10 \mathrm{~min}$ at room temperature, followed by two washes in FACS buffer. Finally, cells were stained with an appropriate combination of anti-IFN- $\gamma$-APC and anti-IL-4-PE for $30 \mathrm{~min}$ at room temperature, washed, and resuspended in FACS buffer for analysis.

\section{Cytokine Concentrations}

IL-4, IL-5, and IL-13 levels in the culture supernatants of cells that were stimulated for $48 \mathrm{~h}$ in bronchoalveolar lavage fluid (BALF) were determined using ELISA kits (R\&D Systems, Minneapolis, MN, USA). IgE anti-OVA Abs were detected using a mouse antiOVA IgE Antibody Assay Kit (Chondrex, Redmond, WA, USA).

\section{mRNA Measurements}

cDNA synthesized from total RNA using the SuperScript III First-Strand Synthesis System (Invitrogen) was used for qRTpolymerase chain reaction (PCR) analysis as described previously (15). Real-time PCR was performed in $25 \mu \mathrm{L}$ reaction volumes containing iQ SYBR-Green Supermix, $200 \mathrm{nM}$ of each primer, and $0.5 \mu \mathrm{L}$ of cDNA. The PCR cycle parameters were $3 \mathrm{~min}$ at $95^{\circ} \mathrm{C}$ and 40 cycles of $30 \mathrm{~s}$ at $95^{\circ} \mathrm{C}, 30 \mathrm{~s}$ at $60^{\circ} \mathrm{C}$, and $30 \mathrm{~s}$ at $72^{\circ} \mathrm{C}$, followed by melting curve analysis. Relative quantification of cytokine mRNA expression was performed using the comparative $\mathrm{Ct}$ method. The relative quantification value of the target in stimulated T cells, normalized to the $\beta$-actin gene expression level (endogenous control) and relative to a calibrator, was expressed as $2^{-\Delta \Delta \mathrm{Ct}}$ (fold), where $\Delta \mathrm{Ct}=\mathrm{Ct}$ of the target gene $-\mathrm{Ct}$ of the endogenous control gene ( $\beta$-actin) and $\Delta \Delta \mathrm{Ct}=\Delta \mathrm{Ct}$ of stimulated samples for target gene $-\Delta \mathrm{Ct}$ of the untreated control as a calibrator for the target gene. All data in stimulated T cells were expressed as arbitrary units relative to the expression level in the corresponding unstimulated $\mathrm{T}$ cells. The primers were as follows: $\beta$-actin: 5'-CCAGCCTTCCTTCTTGGGTAT-3' (forward), 5' -TGGCAT AGAGGTCTTTACGGATGT-3' (reverse); Il4: 5' -TCTCGAATG TACCAGGAGCCATATC-3' (forward), 5' -AGCACCTTGGAA GCCCTACAGA-3' (reverse); Il5: 5' -CGATGAGGCTTCCTGTC CCTA-3' (forward), 5'-TTGGAATAGCATTTCCACAGTACCC-3' (reverse); Ill3: 5'-CAATTGCAATGCCATCTACAGGAC-3' (forward), 5'-CGAAACAGTTGCTTTGTGTAGCTGA-3' (reverse); Gata3: 5'-AGAGATTTCAGATCTGGGCAATGG-3' (forward),
5'-CAGGGACTGATTCACAGAGCATGTA-3' (reverse); Bcl6: 5'-CCGGCTCAATAATCTCGTGAA-3' (forward), 5'-GGTGC ATGTAGAGTGGTGAGTGA-3' (reverse).

\section{Chromatin Immunoprecipitation}

The ChIP assay was performed as previously described $(14,15)$. Protein and chromatin in $\mathrm{T}_{\mathrm{H}}$ cells were cross-linked by adding formaldehyde solution (Thermo Fisher Scientific, Waltham, MA, USA), after which the cells were lysed in SDS lysis buffer. Subsequently, precleared, sonicated chromatin and protein $G$ agarose (Millipore) were incubated with specific Abs for the protein of interest or control IgG (rabbit). Some of the untreated chromatin was used as an input sample. qPCR was used to quantify the DNA region in the immune-precipitated chromatin and the input DNA. Relative ChIP DNA quantification was performed using the comparative $\mathrm{Ct}$ method. The $\mathrm{Ct}$ value of ChIP DNA was normalized to that of the input DNA using the following equation: $\Delta \mathrm{Ct}$ (normalized ChIP) $=\mathrm{Ct}(\mathrm{ChIP})-\mathrm{Ct}$ (input). The normalized Ct values were adjusted to the normalized background Ct value $(\Delta \Delta \mathrm{Ct}[\mathrm{ChIP} / \mathrm{IgG}]=\Delta \mathrm{Ct}$ [normalized ChIP] $-\Delta$ Ct [normalized IgG]). ChIP enrichment above the sample specific background was calculated as $2^{-\Delta \Delta \mathrm{Ct}(\mathrm{ChIP/IgG)}}$ and reported as a fold change. The following primers were used for qPCR: Il5BS: 5'-TGGGCCTTACTTCTCCGTGTAACT-3' (forward), 5'-CTCCAGTGACCCTGATACCTGAAT-3' (reverse); Ill3BS: 5'-TTCTACTAGCTCGGGACTCTTCCA-3' (forward), 5' -ATGGACATGACATGGGAAACCCAG-3' (reverse); BS1: 5' AGGTCCATGGAAGGGACAGATCA-3' (forward), 5' -CGGAT CCTTTCCTGGAATTGCTGA-3' (reverse); BS2: 5' -TCCAATT GGTCTGATTTCACAGGA-3' (forward), 5'-ACACCAGATTG TCAGTTATTCTGGGC-3' (reverse); BS3: 5'-ACAGATGTGAC AGGCTGATAGTGC-3' (forward), 5'-GGCCTTTCATTCTCAG TGGTGTGT-3' (reverse); BS4: 5' -CCTGGCTTCTGAGATGCA ATGAGT-3' (forward), 5' -GGGTAAGAGGAAAGCCAGCATGA-3' (reverse); BS5: 5' -TTCAAGGATAAGCAAGTGGCAGGC-3' (forward), 5' -ATTGGAACTAAGCCAGCCGATGGA-3' (reverse); BS6: 5' -CGCCTCTCCTGTAAGGTACACAAT-3' (forward), 5' TTGCCTTGCAACCATGAAGACCTG-3' (reverse); BS7: 5'-CA CTCACCAATTTGTCTGGAGGCT-3' (forward) 5' -ATGGTGA TCACAGTCCAAGTCCAG-3' (reverse).

\section{Retroviral Vectors With a d2EGFP Reporter Gene}

A genomic fragment of the $I l 4$ promoter (p) region (positions -751 to +1 relative to the transcription start site, MGI: 96556), hcIE (222 bp), and CNS2 (337 bp) were amplified by PCR. The fragment of the Il4 promoter region was subcloned upstream of d2-enhanced GFP (d2EGFP) in the retrovirus vector $\mathrm{pBABE}$ delta Bll(-). Fragments of hcIE (222 bp) or CNS2 (337 bp) were subcloned downstream of $d 2 E G F P$ to generate $\mathrm{pBABE}$ delta Bll(-)-Il4p-d2EGFP-hcIE or pBABE delta Bll(-)-Il4pd2EGFP-CNS2, respectively. pBABE delta $\mathrm{BII}(-)$ is based on pBABEpuro (3) (gifted by Dr. H. von Melchner, University of Frankfurt Medical School). PCR-based mutagenesis of G3 and BS3 in hcIE and BS7 (1) and (2) in CNS2 was achieved using a QuickChange XL Site-Directed Mutagenesis Kit (Stratagene). 
Specifically, a fragment of $d 2 E G F P$ cDNA was PCR amplified using an XhoI-anchored sense primer (underlined) (5'-CCG CTCGAGTCTAGAGGATCCACCGGTCGC-3') immediately upstream of the $\mathrm{XbaI}$ site $(+258)$ and an antisense primer with a SalI-anchored antisense primer (underlined) (5'-ACGC GTCGACTCTAGAGTCGCGGCCGCATC-3') immediately downstream of the XbaI site (+1147) of pd2EGFP. The XhoI/SalI fragment of $d 2 E G F P$ was subcloned into a T Easy vector (d2EGFPT vector). The EcoRI-digested $22 E G F P$ fragment was blunted and subcloned into a blunted NotI/NcoI-restricted pMX vector ( $\mathrm{pMX}$ d2EGFP). A genomic fragment of the Il4 promoter region was PCR amplified using the EcoRI-anchored sense primer (underlined) (5'-GAATTCCTCCACACTGATGCTGTAGTGC-3') and XhoI-anchored antisense primer (underlined) (5' ${ }^{\prime}$ CTCGAGG CTAACAATGCTGGC-3'). The subcloned Il4 promoter fragment was then digested with EcoRI and XhoI and subcloned into the restricted site of pMX-d2EGFP (pMX-Il4p-d2EGFP). An EcoRI and SalI fragment of pMX-Il4p-d2EGFP was then subcloned into the EcoRI/SalI-restricted pBABE delta Bll(-) to generate pBABE delta $\mathrm{Bll}(-)-I l 4 \mathrm{p}-d 2 E G F P$. The vector $\mathrm{pBABE}$ delta $\mathrm{BII}(-)$ is based on pBABEpuro, with further modifications to completely destroy the endogenous transcriptional regulatory sequences within the retroviral long terminal repeat (LTR). R and U5 are the intact R and U5 regions of MMLV, respectively, en. del. U3 is the SIN U3 found in proviral LTRs after integration of the virus into the host genome, and partial LTR denotes a transcription-competent part of the LTR that is used to drive transcription of the genomic viral RNA in the packaging cells. The hcIE genomic fragments were PCR amplified with the XhoI-anchored sense primer (underlined) (5'-CCGCTCGAGCCTTTCTGCCTGCTGCTCTG-3') and SalI-anchored antisenseprimer(underlined) (5'-ACGCGTCGAC GAAAAGCAGGCAGTCTGGAG-3').

Conserved noncoding sequence 2 fragments were obtained by PCR using the XhoI-anchored sense primer (underlined) (5' -CCGCTCGAGCTGGAGATTAGAAGTGGAGGCT-3') and SalI-anchored antisense primer (underlined) (5'-ACGC GTCGACTTTCCTGTCCTCGTCTTTTCCAGT-3'). The hcIE and CNS2 fragments were then inserted in SalI-digested pBABE delta Bll(-)-Il4p-d2EGFP to generate pBABE delta Bll(-)-Il4p-d2EGFP-hcIE and pBABE delta Bll(-)-Il4pd2EGFP-CNS2, respectively, for reporter gene assays. PCR-based mutagenesis of G3 (5'-CTGATAGTG-3': +1247 to +1255), BS3 (5'-TTCATGGAA-3': +1328 to +1336$)$ in hcIE, and BS7 (1) (5'-GTTTTTGAA-3': +12941 to +12949) and BS7 (2) (5'-TTCCTGGA-3': +13142 to +13149$)$ in CNS2 in the reporter plasmid were generated using a QuickChange XL Site-Directed Mutagenesis Kit according to the manufacturer's instructions. The underlined nucleotides were substitutes for CTAT for G3 and TT for BS3 and BS7 to generate pBABE delta Bll(-)-Il4pd2EGFP-hcIE-MutBS3, pBABE delta Bll(-)-Il4p-d2EGFP-hcIEMutG3, pBABE delta Bll(-)-Il4p-d2EGFP-CNS2-MutB7 (1), and pBABE delta Bll(-)-Il4p-d2EGFP-CNS2-MutB7 (2), respectively. Successful PCR and mutation were verified by DNA sequencing.

\section{Retrovirus Infection}

Platinum-E packaging cells (32) were transfected with 1-1.5 $\mu \mathrm{g}$ of DNA of a retrovirus construct mixed with $6 \mu \mathrm{L}$ of Fugene
(Boehringer Mannheim). Virus supernatant was concentrated by centrifugation $(8,000 \times g, 16 \mathrm{~h})$ and added to $\mathrm{T}_{\mathrm{H}} 2$ cell-inducing cultures on day 2. Intracellular cytokine staining or mean fluorescence intensity (MFI) analysis was performed on day 7 as described previously. Infected cells were subjected to FACS analysis of the intracellular fluorescence of d2EGFP $8 \mathrm{~h}$ after restimulation with plate-bound anti-CD3 mAbs.

\section{Western Blot Analysis}

In vitro-differentiated $\mathrm{T}_{\mathrm{H}} 2$ cells were lysed with lysis buffer $(1 \%$ Nonidet P-40, 5\% glycerol, 50 mM Tris- $\mathrm{HCl}, \mathrm{pH}$ 7.5, $100 \mathrm{mM}$ $\mathrm{NaCl}, 10 \mu \mathrm{g} / \mathrm{mL}$ leupeptin, $0.1 \mathrm{mM}$ phenylmethylsulfonyl fluoride, $1 \mathrm{mM}$ dithiothreitol, $1 \mu \mathrm{g} / \mathrm{mL}$ pepstatin $\mathrm{A}, 10 \mathrm{mM}$ $\mathrm{Na}_{3} \mathrm{VO}_{4}$, and $10 \mathrm{mM} \mathrm{NaF}$ ). For immunoblotting, anti-Bcl6 or anti- $\beta$-tubulin $\mathrm{Ab}$ was used. Immunoreactive bands were visualized using a Phototope-HRP Western Blot Detection System (Cell Signaling Technology). For quantitative analysis of Western blots, the intensities of individual bands were quantified using ImageJ software (National Institutes of Health, Bethesda, MD, USA).

\section{Antigen-Induced Airway Inflammation OVA Challenge and Bronchoalveolar lavage (BAL)}

$\mathrm{T}_{\mathrm{H}} 2$ cells $\left(1.5 \times 10^{7}\right.$ or $\left.3 \times 10^{7}\right)$ were injected intravenously into naïve wild-type (WT) BALB/c mice (day 0 ), followed by intratracheal challenge with $1 \%$ OVA solution $(50 \mu \mathrm{L})$ twice (days 2 and 3), BAL three times (days 2, 7, and 12), and serum collection. On days 4 and 5 , the transferred $\mathrm{T}_{\mathrm{H}} 2$ cells isolated from whole lungs and BALF were collected from the mice by instilling the lungs with $0.5 \mathrm{~mL}$ of PBS six times. Sera on day 14 were analyzed for OVA antigen-specific IgE Abs. In another experiment, a mixture of Bcl6-WT, Bcl6-TG, or Bcl6-KO KJ1-26+ MPT $\left(2 \times 10^{6}\right.$ cells $)$ and Bcl6-WT KJ1-26- naïve CD4 ${ }^{+} \mathrm{T}\left(5 \times 10^{6}\right.$ cells) cells were intravenously transferred into BALB/c nu/nu mice (day 0). Subsequently, mice were sensitized via i.p. injection of $10 \mu \mathrm{g}$ of OVA plus $1 \mathrm{mg}$ of alum twice (days 1 and 6), followed by intratracheal challenge with OVA twice (days 16 and 17). BAL and pathology examination were performed (day 18), and transferred $\mathrm{KJ}^{-26^{-}}$cells were isolated from spleens (day 16). The isolated cells were restimulated with plate-bound anti-CD3 mAbs to analyze cytokine production. The BALF supernatant was stored at $-80^{\circ} \mathrm{C}$. Each cell pellet was resuspended in PBS for counting and subjected to cytospin. Preparations on slides were stained with Diff-Quick (Sysmex International Reagents, Kobe, Japan) for the differential analysis of cell counts. After BAL, lungs were treated with collagenase II $(1 \mathrm{mg} / \mathrm{mL})$ for $30 \mathrm{~min}$ at $37^{\circ} \mathrm{C}$, and leukocytes were isolated on a Percoll gradient.

\section{Histologic Examination}

After BAL, the left lobes of lungs were extracted, washed with PBS, and fixed in $4 \%$ formaldehyde in sodium phosphate buffer for more than 2 days at room temperature. After fixation, lungs were embedded in paraffin and stained with hematoxylin and eosin. Images of each tissue section were captured using a Zeiss Axioscope 2 microscope equipped with a video camera (AxioCam ERc5s, Carl Zeiss, Jena, Germany) and processed using Axiovision V.4 software (Carl Zeiss). 


\section{Statistical Analysis}

Statistical significance was determined using $t$-tests (two-tailed) for two groups and Tukey-Kramer or Steel-Dwass multiple comparisons tests for three or more groups. $P$ values $<0.05$ were considered significant.

\section{RESULTS}

\section{Bcl6 Represses IL-4 Production by MPT Cells}

Splenic CNS2-active MPT cells were detected as a $\mathrm{GFP}^{+}$subpopulation in reporter gene TG mice (CNS2-GFP-TG) on each Bcl6 genotype background (28) (Figure 1A). Unfortunately, offspring from CNS2-GFP-TG mice on the Bcl6-KO background could not be obtained (Figure 1B). Although the percentages of $\mathrm{GFP}^{+}$cells were similar between $B c l 6-\mathrm{TG}$ and Bcl6-WT mice (Figure 1C), the IL- $4^{+}$MPT cell frequency (Figure 1D) and MFI of CNS2GFP in MPT cells (Figure 1E) were inversely correlated with Bcl6 levels. $\mathrm{GFP}^{+} \mathrm{MPT}$ cells displayed significant $\mathrm{Il} 4$ expression, which was lower in Bcl6-TG cells than in WT cells (Figure 1F). Il4 expression was extremely low in the $\mathrm{GFP}^{-}$population regardless of Bcl6 levels. The absolute numbers and percentages of IL $-4^{+}$MPT cells were also negatively associated with Bcl6 levels (Figure 1G), whereas the absolute numbers of $\mathrm{GFP}^{+} \mathrm{MPT}$ cells (Figure 1H) and MPT cells (Figure 1I) among all CD4 ${ }^{+} \mathrm{T}$ cells
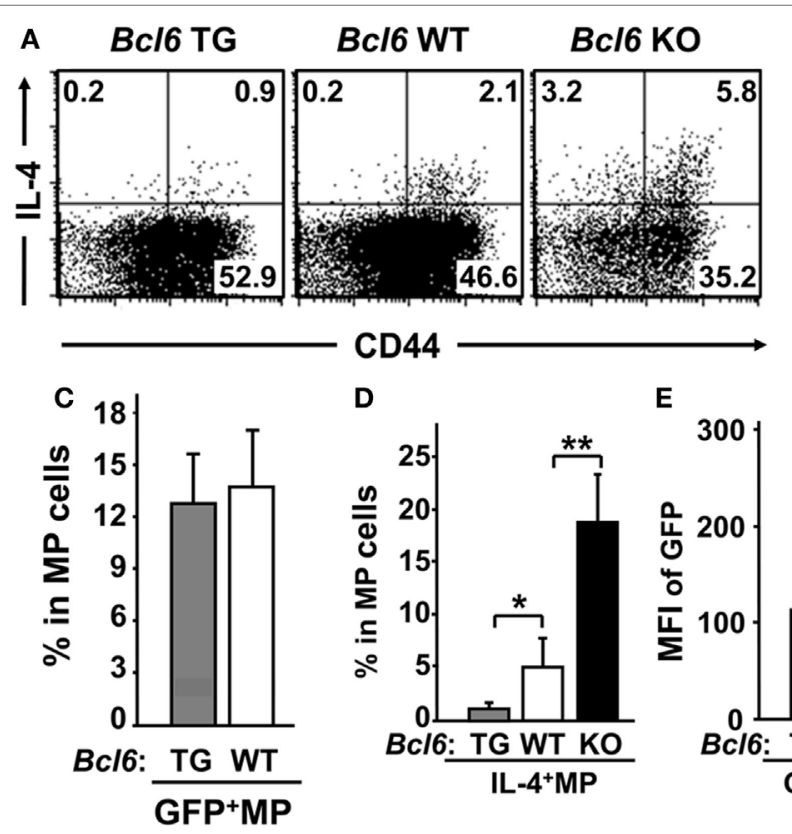

D

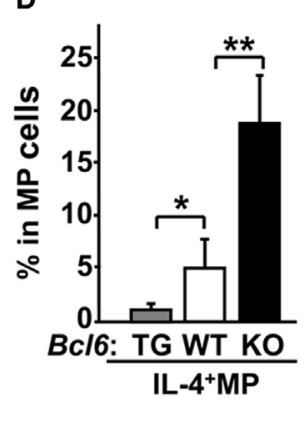

E

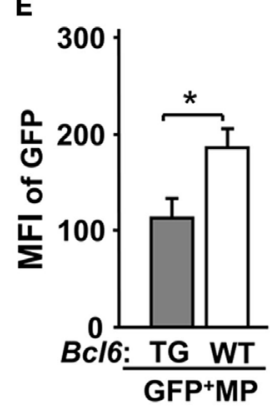

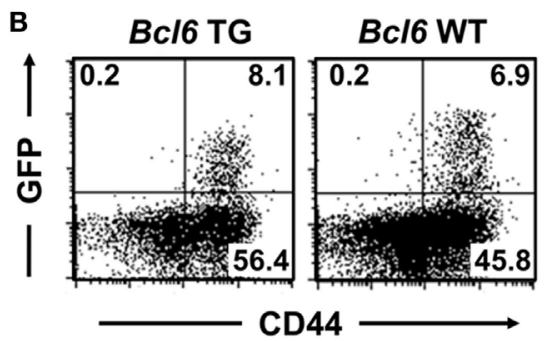

$\mathbf{F}$

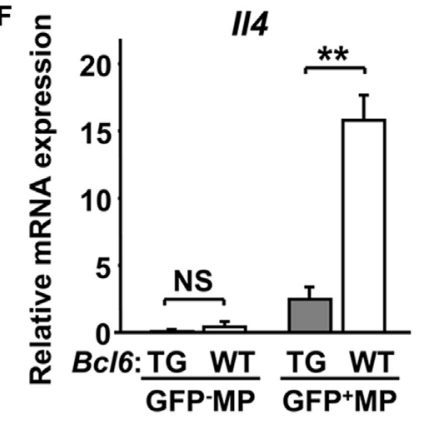

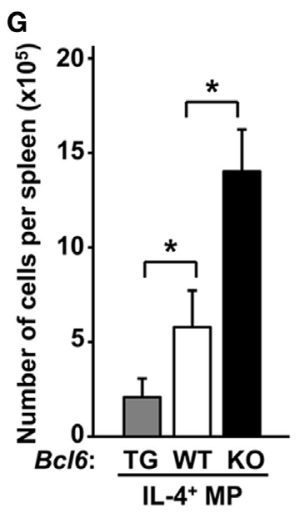
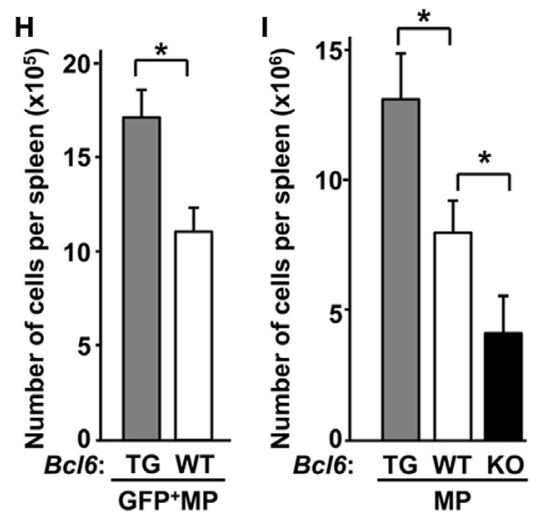

FIGURE 1 | IL-4+ MPT cells in mice with varying genetic Bc/6 expression. (A,B) FACS analysis of intracellular IL-4+ [(A) Bc/6-TG, Bc/6-WT, and Bc/6-KO] and CNS2-activation-related GFP ${ }^{+}[(\mathbf{B})$ Bc/6-TG and Bcl6-WT] MPT cells in a CD44 high population by gating CD4+ CD49b- T splenocytes at rest. The presented data are representative of four independent experiments. The numbers in the corners represent the percentages of gated T cells. (C,D) Frequency of GFP+ $[(\mathbf{C}) B$ Cl6-TG and Bc/6-WT] and IL-4+ [(D) Bc/6-TG, Bc/6-WT, and Bc/6-KO] MPT cells. (E) MFI of GFP in MPT cells from Bc/6-TG and Bc/6-WT mice. (F) qRT-PCR analysis of the relative expression of I/4 in GFP- and GFP+ MPT cells from Bc/6-TG and Bc/6-WT spleens. (G-I) Absolute cell numbers of populations of IL-4+ [(G) $B c / 6-\mathrm{TG}$, Bcl6-WT, and Bc/6-KO], GFP ${ }^{+}\left[\mathbf{( H )} B c / 6-\mathrm{TG}\right.$ and Bcl6-WT], and total (I) MPT cells in one spleen. Data are presented as the mean \pm SEM $(n=7-9) .{ }^{*} P<0.05$; ${ }^{\star \star} P<0.01$, comparison between two groups as indicated. Bcl6, B-cell lymphoma 6; CNS, conserved noncoding sequence; FACS, fluorescence-activated cell sorting; GFP, green fluorescent protein; KO, knockout; MFI, mean fluorescence intensity; MPT cell, memory phenotype CD4+ T cell; NS, not significant; TG, transgenic; WT, wild-type. 
were positively correlated with Bcl6 levels. Therefore, Bcl6 may be involved in Il4 downregulation in MPT cells and MPT cell survival and maintenance. Because it has been reported that the $\mathrm{T}_{\mathrm{H}} 2$ and $\mathrm{T}_{\mathrm{H}} 1$ conditions are promotive and inhibitory, respectively, on the maintenance of Bcl6-WT CNS2-GFP ${ }^{+}$MPT cells (28), we analyzed the effect of $\mathrm{Bcl} 6$ on the maintenance of CNS2-GFP ${ }^{+}$ MPT cells in each culture setting (Figure S1 in Supplementary Material). Regarding the maintenance of $\mathrm{GFP}^{+}$cells, a promoting effect of the $\mathrm{T}_{\mathrm{H}} 2$ condition and inhibitory effect of $\mathrm{T}_{\mathrm{H}} 1$ condition were observed regardless of the Bcl6 genotype, whereas Bcl6 appears to function as a suppressor for CNS2 activity.

\section{Bcl6 Represses I/4 Expression in $\mathrm{T}_{\mathrm{H}}$ 2-Primed MPT Cells}

To investigate the function ofBcl6in the differentiation of MPT cells into $\mathrm{T}_{\mathrm{H}}$ cell lineages following TCR stimulation, MPT cells expressing a clonotypic TCR $\left(\mathrm{KJ} 1-26^{+}\right)$from the spleens of Bcl6-TG, Bcl6-KO, and Bcl6-WT DO11.10 TG mice were cultured under conditions driving them toward the $\mathrm{T}_{\mathrm{H}} 0, \mathrm{~T}_{\mathrm{H}} 1$, or $\mathrm{T}_{\mathrm{H}} 2$ phenotype, followed by intracellular IL-4 analysis after restimulation with anti-CD3 mAbs (Figures 2A,B). Under the $\mathrm{T}_{\mathrm{H}} 0$ condition, Bcl6 decreased IL-4 production in a concentration-dependent manner, and high Bcl6 expression facilitated IFN- $\gamma$ induction during
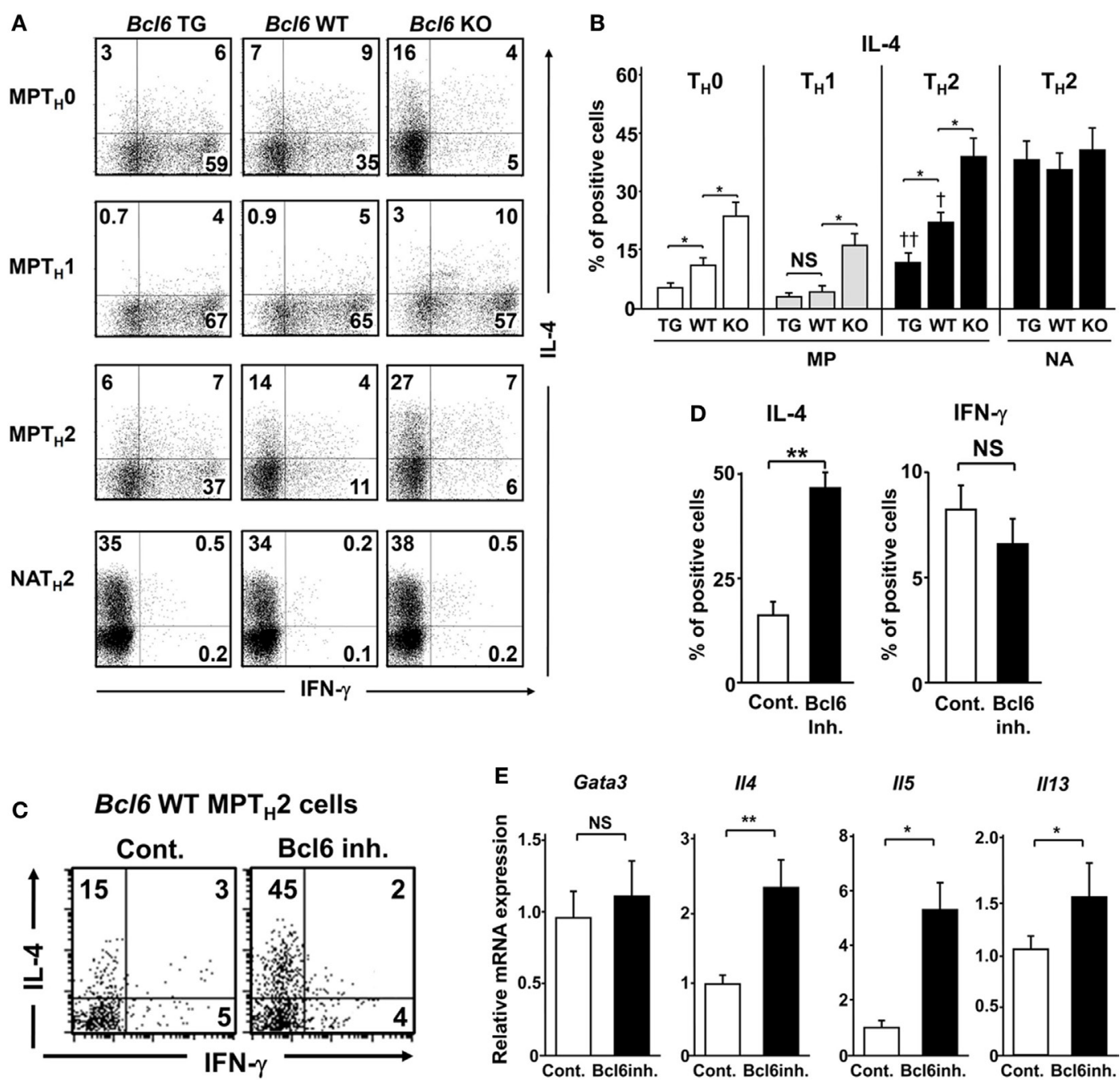

FIGURE 2 | Regulatory role of Bcl6 in the differentiation of TH2 cells. (A-E) KJ1-26+ MPT and NA T cells (CD4+ CD44 $\left.{ }^{\text {low }} \mathrm{CD}^{+} \mathrm{L}^{+}\right)$among splenocytes from Bc/6-TG, Bcl6-WT, and Bc/6-KO DO11.10 mice cultured with ovalbumin peptides and antigen-presenting cells in vitro for 7 days to produce $T_{H} 0, T_{H} 1$, and $T_{H} 2$ cells. Cells were restimulated with anti-CD3 monoclonal antibodies. After $8 \mathrm{~h}$, IL-4- and IFN- $\gamma$-producing cells among gated KJ1-26+ CD4+ T cells were analyzed by FACS. (C-E) Analysis of cytokine production by Bcl6-WT MPT 2 cells treated with a Bcl6 inhibitor (inh.) for $12 \mathrm{~h}$ prior to restimulation. (A,C) Numbers in the corners represent percentages among gated T cells. (B,D) Percentage of IL-4+ (Bc/6-TG, Bc/6-WT, and Bc/6-KO) cells for each TH cell type (B) and IL-4+ and IFN- $\gamma^{+}$ Bcl6-WT MPT 2 cells cultured with or without Bcl6 inhibitor (D). (E) qRT-PCR analysis of the relative expression of Gata3, II4, I/5, and I/13 in restimulated Bcl6-WT $\mathrm{MPT}_{\mathrm{H}} 2$ cells treated with or without a Bcl6 inhibitor. Data are presented as the mean $\pm \mathrm{SEM}(n=7-8) .{ }^{*} P<0.05,{ }^{*} P<0.01$, comparison between two groups is indicated; ${ }^{\dagger} P<0.05$, compared with $B c / 6-W T$. All results are representative of five independent experiments with similar outcomes, excluding (C), for which four experiments were conducted. Bcl6, B-cell lymphoma 6; Cont., control; FACS, fluorescence-activated cell sorting; KO, knockout; MPT cell, memory phenotype CD4+ T cell; MPT 2 cell, MPT cell-derived $T_{H} 2$ cell; NA, naïve; TG, transgenic; $W T$, wild-type. 
$\mathrm{T}_{\mathrm{H}} 1$ phenotype differentiation. Under the $\mathrm{T}_{\mathrm{H}} 1$ condition, $\mathrm{Bcl} 6$ deficiency in MPT cells preserved IL-4 production, although its level was lower than that under the $\mathrm{T}_{\mathrm{H}} 0$ condition. Under the $\mathrm{T}_{\mathrm{H}} 2$ condition, Bcl6 negatively regulated MPT cell-derived $\mathrm{T}_{\mathrm{H}} 2$ $\left(\mathrm{MPT}_{\mathrm{H}} 2\right)$ cell differentiation but not $\mathrm{NAT}_{\mathrm{H}} 2$ differentiation, as previously reported (15) (Figures 2A,B), although Bcl6 could suppress the initial IL-4 production by naïve CD4 T cells under the $\mathrm{T}_{\mathrm{H}} 0$ condition even when blocking the effects of IFN- $\gamma$ (Figure S2 in Supplementary Material). Because Bcl6 appears to promote IFN- $\gamma$ production, which may indirectly affect IL- 4 induction, we analyzed a mixed culture of Bcl6-WT MPT cells with either Bcl6TG or Bcl6-KO cells under the $\mathrm{T}_{\mathrm{H}} 0$ condition. Bcl6-KO MPT cells caused WT cells to skew clearly toward the $\mathrm{T}_{\mathrm{H}} 2$ phenotype with reduced $\mathrm{T}_{\mathrm{H}} 1$ skewing, whereas $B$ cl6-TG cells promoted slight $\mathrm{T}_{\mathrm{H}}$ skewing (Figure S3 in Supplementary Material), indicating that increased IL-4 production in Bck6-KO MPT cells autoaccelerates $\mathrm{T}_{\mathrm{H}} 2$ cell differentiation by preventing $\mathrm{T}_{\mathrm{H}} 1$ cell differentiation. Thus, Bcl6 appears to promote IFN- $\gamma$ production by inhibiting IL-4 production rather than inhibiting IL-4 production via the promotion of IFN- $\gamma$ production.

To confirm the suppressive effects of $\mathrm{Bcl} 6$ on $\mathrm{T}_{\mathrm{H}} 2$ cytokine genes in $\mathrm{MPT}_{\mathrm{H}} 2$ cells, Bcl6-WT $\mathrm{MPT}_{\mathrm{H}} 2$ cells were treated with a Bcl6 inhibitor (15), followed by restimulation with anti-CD3 mAbs. Bcl6 inhibition augmented IL-4 production but not IFN- $\gamma$ production (Figures 2C,D). $\mathrm{T}_{\mathrm{H}} 2$ cytokine gene expression was upregulated by the inhibitor without changes in Gata3 expression (Figure 2E), indicating that Bcl6 suppresses Il4 expression in developing and differentiated $\mathrm{MPT}_{\mathrm{H}} 2$ cells.

\section{Bcl6 Negatively Regulates the Histone Modification of $\mathrm{T}_{\mathrm{H}} 2$ Cytokine Loci in MPT $_{\mathrm{H}} 2$ Cells}

Because unprimed MPT cells express higher Bcl6 levels than naïve CD4 ${ }^{+} \mathrm{T}$ cells (29), Bcl6 expression levels in the MPT and $\mathrm{MPT}_{\mathrm{H}} 2$ cells of CNS2-GFP-TG mice with Bcl6-WT background were analyzed at rest (Figure 3A). Bcl6 expression in $\mathrm{GFP}^{+} \mathrm{MPT}$ and $\mathrm{GFP}^{-} \mathrm{MPT}_{\mathrm{H}} 2$ cells was increased by sevenfold and threefold, respectively, compared with that in $\mathrm{GFP}^{+} \mathrm{MPT}_{\mathrm{H}} 2$ cells. $\mathrm{NAT}_{\mathrm{H}} 2$ cells had markedly lower Bcl6 expression than $\mathrm{GFP}^{+} \mathrm{MPT}_{\mathrm{H}} 2$ cells. Bcl6 expression in $\mathrm{GFP}^{+} \mathrm{MPT}$ cells was slightly increased compared with that in $\mathrm{GFP}^{-}$MPT cells. Consistent with the mRNA levels, Bcl6 protein expression was lower in $\mathrm{GFP}^{+} \mathrm{MPT}_{\mathrm{H}} 2$ cells than in $\mathrm{GFP}^{-} \mathrm{MPT}_{\mathrm{H}} 2$ cells (Figure 3B). Bcl6 protein levels in MPT cells from Bcl6-WT mice were higher than those in $\mathrm{MPT}_{\mathrm{H}} 2$ cells, whereas the protein levels in $\mathrm{GFP}^{+} \mathrm{MPT}$ cells were slightly higher than those in $\mathrm{GFP}^{-}$MPT cells. To address Bcl6 function, $\mathrm{T}_{\mathrm{H}} 2$ cytokine production by $\mathrm{MPT}_{\mathrm{H}} 2$ cells from Bcl6WT-CNS2-GFP-TG mice was analyzed. $\mathrm{T}_{\mathrm{H}} 2$ cytokine protein (Figure 3C) and transcript levels (Figure 3D) were significantly greater in the $\mathrm{GFP}^{+}$population than in the $\mathrm{GFP}^{-}$population following stimulation, implying that Bcl6 function may be inhibited depending on its quantity and/or quality and that this inhibition may be involved in $\mathrm{T}_{\mathrm{H}} 2$ cytokine production in $\mathrm{MPT}_{\mathrm{H}} 2$ cells. Conversely, IFN- $\gamma$ protein (Figure 3C) and transcript levels (Figure 3D) were undetectable and minimal, respectively, in both the $\mathrm{GFP}^{+}$and $\mathrm{GFP}^{-}$populations. Because Bcl6 binds to
BSs (except BSIL13) (Figure 3E, top) and thereby reduces $\mathrm{T}_{\mathrm{H}} 2$ cytokine production in $\mathrm{NAMT}_{\mathrm{H}} 2$ cells (15), Bcl6 binding to each site in $\mathrm{MPT}_{\mathrm{H}} 2$ cells was analyzed by ChIP (Figure $3 \mathrm{E}$, bottom). In Bcl6-WT and Bcl6-TG $\mathrm{MPT}_{\mathrm{H}} 2$ cells, Bcl6 binding was observed at all BS sites excluding BSIL13, BS1, and BS2. $\mathrm{GFP}^{+}$cells had significantly less Bcl6 binding than $\mathrm{GFP}^{-}$cells among Bcl6-WT and $B c l 6-\mathrm{TG} \mathrm{MPT}_{\mathrm{H}} 2$ cells, whereas Bcl6 binding was augmented

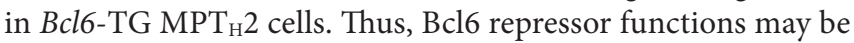
regulated qualitatively (e.g., its binding ability) and quantitatively by its binding to $\mathrm{T}_{\mathrm{H}} 2$ cytokine gene foci. To investigate the effects of Bcl6 of STATs on histone modification in these foci, ChIP was performed for STAT5 and STAT6 binding to BSs and for histone $\mathrm{H} 3$ acetylation in $\mathrm{MPT}_{\mathrm{H}} 2$ cells (Figure 3F). STAT6 binding was marginal, whereas STAT5 binding was significantly decreased depending on Bcl6 levels, as indicated by attenuated histone acetylation.

\section{Bcl6 Represses I/4 Expression by Binding to CNS2 in MPT $_{\mathrm{H}} 2$ Cells}

B-cell lymphoma 6, but not STAT proteins, binds to BS7 (Figures 3D,E) in the major Il4 regulatory region. Although no significant Bcl6-mediated interaction was observed between BS7 in CNS2 regarding Il4 regulation in $\mathrm{NAMT}_{\mathrm{H}} 2$ cells (15), CNS2 enhancer activity may be suppressed by Bcl6 through BS7 binding. FACS analysis indicated that GFP MFI levels related to CNS2 activation in MPT cells, including at two mutated sites, namely, BS7 (1) and (2) (Figure 4A), were inversely correlated with Bcl6 levels (Figure 1E). Therefore, the role of Bcl6 in enhancing activity in $\mathrm{MPT}_{\mathrm{H}} 2$ cells from $\mathrm{Bcl6}-\mathrm{WT}$ or $\mathrm{Bcl6}-\mathrm{KO}$ mice was investigated using a retrovirus reporter gene transfer vector (Figure 4B) designed to assess Il4 promoter ( $\mathrm{p}$ ) activity by measuring the MFI for d2EGFP, a reporter protein, following stimulation with anti-CD3 and anti-CD28 mAbs (Figures 4C,D). Additionally, a CNS2 sequence containing WT or mutated BS7, that is, Mu-BS7 (1)-CNS2 and Mu-BS7 (2)-CNS2, were inserted downstream of $d 2 E G F P$ (Figure 4B). The MFI for d2EGFP with CNS2-WT elements in Bcl6-KO cells was higher than that in Bcl6-WT cells. The MFI was augmented by mutations in both BS7 (1) and (2) in $B c l 6$-WT cells, whereas that of Bcl6-KO cells was not significantly changed (Figures 4C,D). Thus, Bcl6 mediated CNS2 suppression in $\mathrm{MPT}_{\mathrm{H}} 2$ cells and presumably in unprimed MPT cells.

\section{Bcl6 Represses I/4 Expression by Binding to hclE in MPT 2 Cells}

Another Il4 regulatory region, HS2 (1.2 kbp) located in intron 2 , is a critical regulatory region for GATA3 binding-mediated Il4 expression in $\mathrm{NAT}_{\mathrm{H}} 2$ cells in HS2-KO mice (33) (Figure 5A, top). A $222 \mathrm{bp}$ DNA sequence of the hcIE region (Mouse Genome Informatics accession no. 5897323) (15) including BS3 and the GATA site (G3) in HS2 (Figure 5A, top) was studied. Gata3 expression was low in unprimed MPT cells from Bcl6-WT and Bcl6-TG mice regardless of CNS2 activation, whereas MPT cells under the $\mathrm{T}_{\mathrm{H}} 2$ condition exhibited similar Gata3 gene induction in Bcl6-WT and Bcl6-TG cells. Gene expression was augmented, particularly in $\mathrm{GFP}^{+}$cells, and attenuated in a Bcl6-dependent manner in $\mathrm{MPT}_{\mathrm{H}} 0$ cells. However, further Gata3 expression 
A

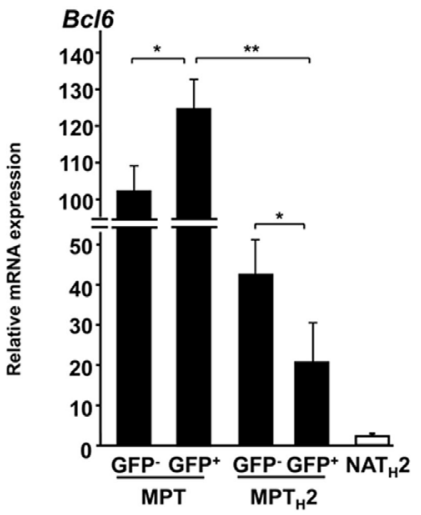

B

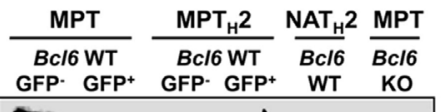

BCI6
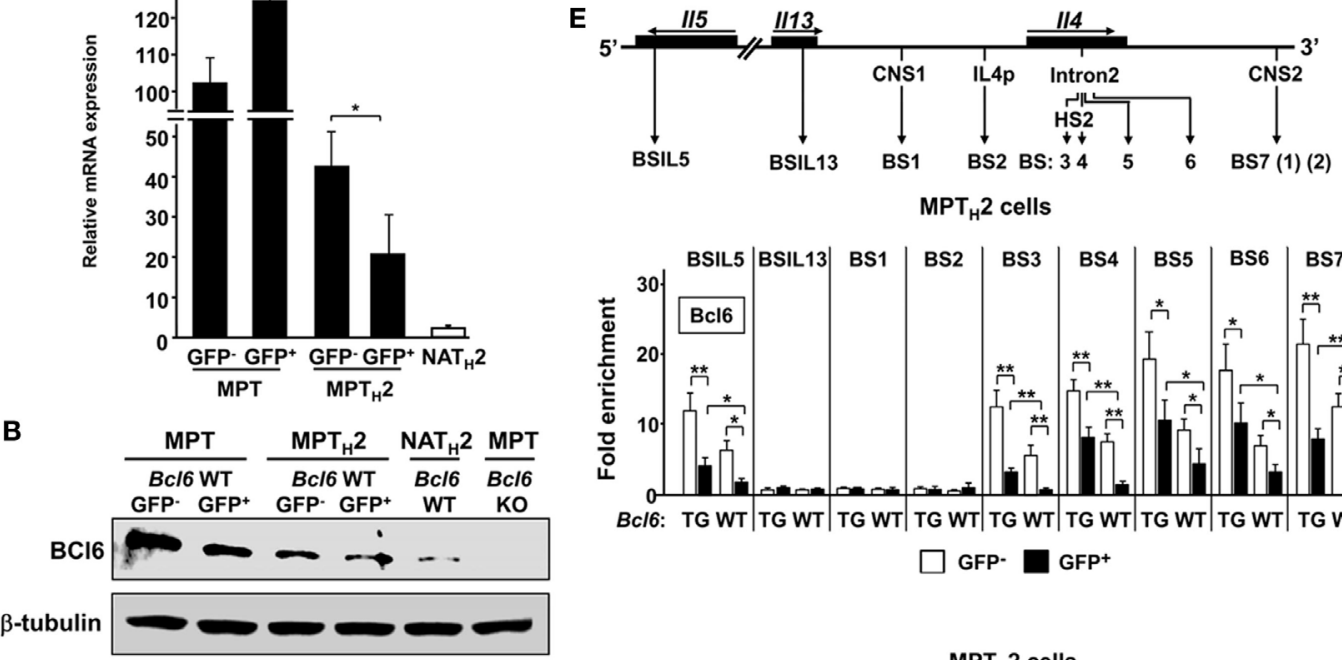

$M \mathrm{PT}_{\mathrm{H}} 2$ cells

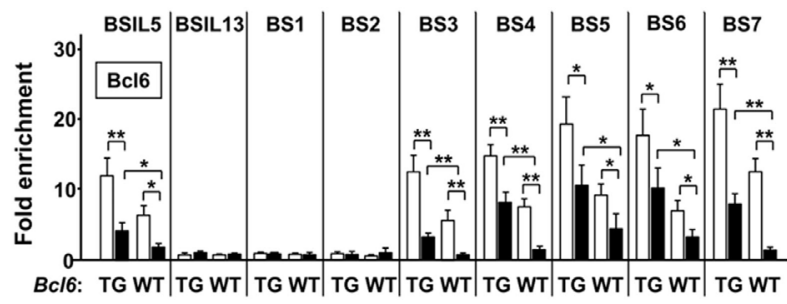

GFP-

GFP+

C

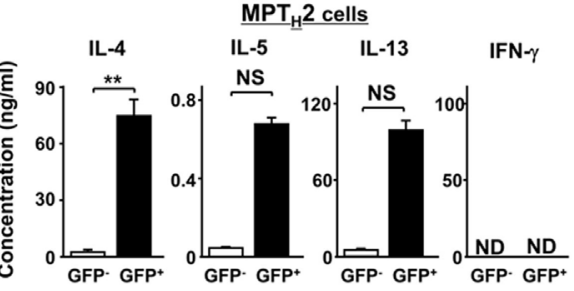

D
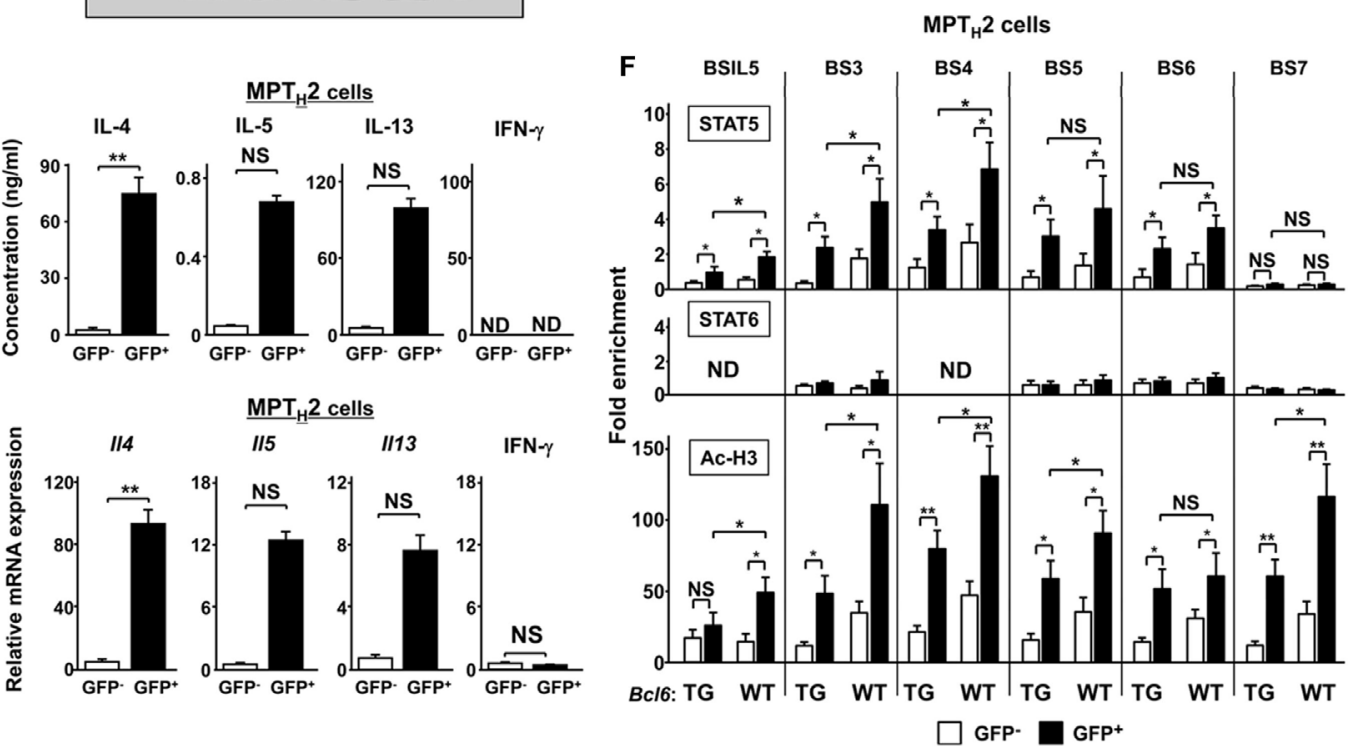

FIGURE 3 | Role of Bcl6 and signal transducer and activator of transcription (STAT) binding to the $/ 14$ locus MPT cells. (A) Bc/6 mRNA levels in GFP+ and GFP- MPT cells, GFP+ and GFP- MPT 2 cells, and NA TH2 cells, as measured by qRT-PCR. (B) Western blot analysis of Bcl6 protein in GFP+ and GFP- MPT cells MPT (Bc/6-WT) and MPT cells (BC/6-KO) in the spleen and GFP+ and GFP- MPT 2 cells (Bc/6-WT). Data are representative of three independent experiments. (C,D) KJ1-26+ cells among MPT cells from the spleens of Bcl6-WT-CNS2-GFP-TG DO11.10 mice were cultured with ovalbumin peptides and antigen-presenting cells in vitro for 7 days under $\mathrm{T}_{\mathrm{H}} 2$ conditions. Cells were restimulated with anti-CD3 and anti-CD28 monoclonal antibodies. After $48 \mathrm{~h}$, IL-4, IL-5, IL-13, and IFN- $\gamma$ levels in culture supernatants were measured by ELISA (C). After $8 \mathrm{~h}$, the mRNA levels of $\| 14$, $115, \| 13$, and lfn- $\gamma$ were measured by qRT-PCR (D). [(E), top] Diagram of $\mathrm{T}_{\mathrm{H}} 2$ cytokine gene loci, with regulatory regions indicated by arrows [CNS, gene promoter regions (p), and Bcl6/STAT (BSs): IL5BS in I/5; IL13BS in //13 intron 1; BS1 and BS7 (1) (2) in CNS1 and CNS2, respectively; BS2 in /14p; and BS3, BS4, and BS5 in /14 intron 2]. (E,F) Bcl6 levels [(E) bottom], STAT5 and STAT6 binding, and $\mathrm{Ac}-\mathrm{H} 3 \mathbf{( F )}$ at each BS were analyzed by chromatin immunoprecipitation assay for CNS2-active (GFP+) (closed bar) and CNS2-inactive (GFP-) (open bar) MPT 2 cells. All results are representative of three $(\mathbf{A}, \mathbf{C}, \mathbf{D})$ or four $(\mathbf{E}, \mathbf{F})$ independent experiments with similar outcomes. Data are presented as the mean \pm SEM $(n=7-9)$. ${ }^{\star} P<0.05,{ }^{* *} P<0.01$, comparison between two groups is indicated. Ac-H3, acetylated histone H3; CNS, conserved noncoding sequence; BS, binding sequence; Bcl6, B-cell lymphoma 6; GFP, green fluorescent protein; KO, knockout; ND, not detected; MPT cell, memory phenotype CD4+ T cell; MPT 2 cell, MPT cell-derived $T_{H} 2$ cell; NA, naïve; TG, transgenic; WT, wild-type.

in $\mathrm{MPT}_{\mathrm{H}} 2$ cells was not significantly affected by Bcl6 levels (Figure 5A, bottom). We investigated the enhancer activity using a reporter construct, uncovering that Bcl6 inhibited hcIE function in $\mathrm{MPT}_{\mathrm{H}} 2$ cells (Figures $\mathrm{S} 4 \mathrm{~A}-\mathrm{C}$ in Supplementary Material). Similarly, ChIP demonstrated that GATA3 binding to G3 was increased in $\mathrm{CNS} 2$-active $\mathrm{GFP}^{+} \mathrm{MPT}_{\mathrm{H}} 2$ cells compared with that in unprimed $\mathrm{GFP}^{+} \mathrm{MPT}$ cells and was significantly attenuated in Bcl6-TG background cells (Figure 5B). Thus, Bcl6 repressed Il4 expression by downregulating GATA3-mediated hcIE activity in $\mathrm{MPT}_{\mathrm{H}} 2$ but not MPT cells. 


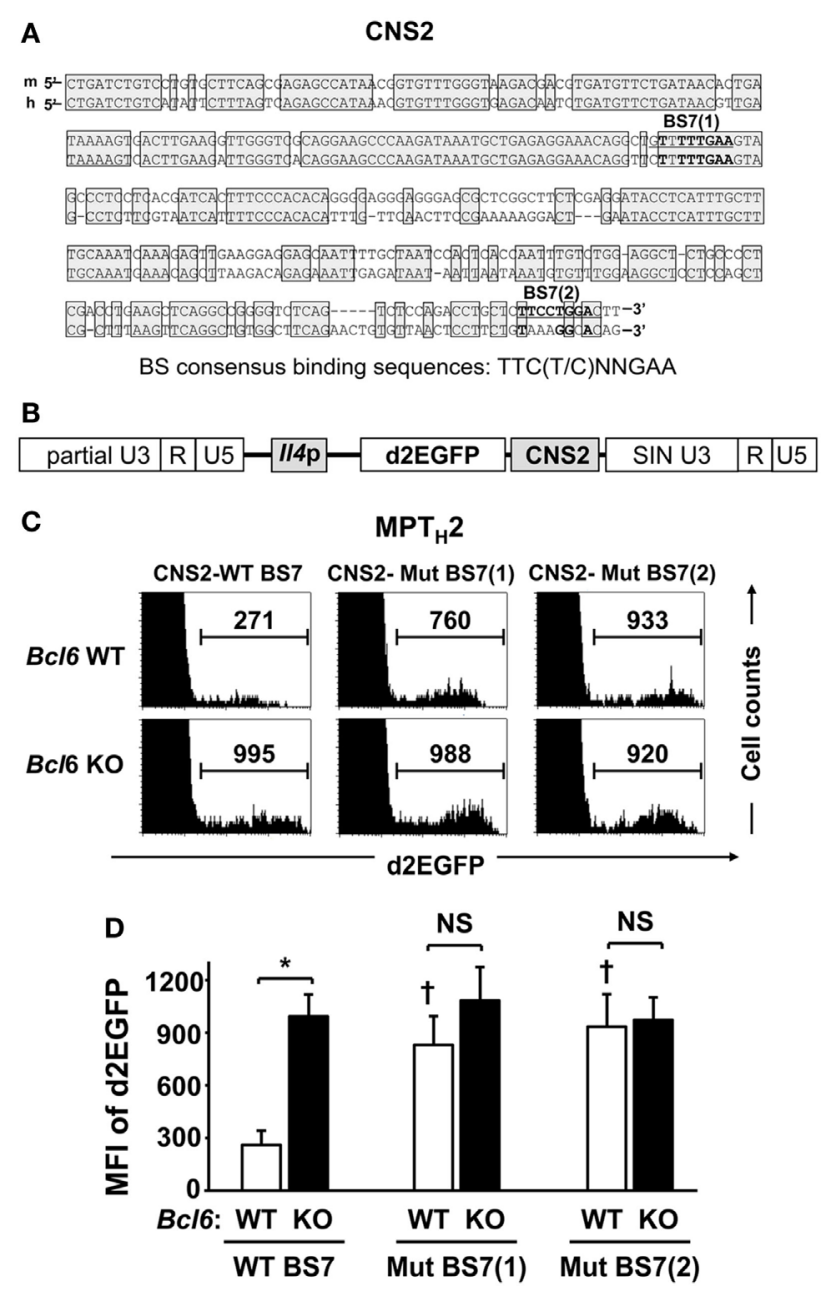

FIGURE 4 | Role of Bcl6 in the CNS2 enhancer activity of MPT 2 cells. (A) A conserved sequence (positions +12805 to +13151 relative to the transcription start site; Mouse Genome Informatics accession no. 96556) in the CNS2 region of mice is shown with human CNS2, including BS7 (1) and (2). Conserved sequences between mice and humans are indicated by shaded boxes. (B,C) Splenic Bc/6-KO and Bc/6-WT MPT cells were cultured under $T_{H} 2$ conditions, and a retrovirus containing the d2EGFP reporter gene, with CNS2-WT BS7 (B), CNS2-Mut BS7 (1), or CNS2-Mut BS7 (2), was introduced into $T_{H} 2$ cells on day 2 of culture. After 7 days of culture, cells were restimulated with anti-CD3 monoclonal antibodies for $8 \mathrm{~h}$ and subjected to FACS analysis of the intracellular MFI of d2EGFP. (C) Histograms of FACS analysis are representative of eight to nine independent experiments. Numbers in each column represent the MFI of d2EGFP. (D) Mean values of the MFI of d2EGFP are indicated. Data are presented as the mean \pm SEM ( $n=8-9$ ). ${ }^{*} P<0.05$, comparison between two groups is indicated; ${ }^{\dagger} P<0.05$, compared with CNS2-WT. Bcl6, B-cell lymphoma 6; CNS, conserved noncoding sequence; d2EGFP, d2-enhanced green fluorescent protein; FACS, fluorescence-activated cell sorting; MFI, mean fluorescence intensity; MPT, memory phenotype CD4+ $\mathrm{T}$; MPT 2 cell, MPT cell-derived $\mathrm{T}_{\mathrm{H}} 2$ cell; Mut, mutant; KO, knockout; WT, wild-type.

To further examine the role of hcIE in $\mathrm{T}_{\mathrm{H}} 2$ cytokine production, we generated hcIE-KO mice and observed markedly diminished IL-4 production in hcIE-KO NAT 2 and $\mathrm{NAMT}_{\mathrm{H}} 2$ cells (15). Intracellular cytokine analysis revealed a similar frequency of IL- $4^{+}$populations in unprimed MPT cells in WT and hcIE-KO background mice, whereas IL-4 $4^{+} \mathrm{MPT}_{\mathrm{H}} 2$ cell development was impaired without changes in Gata3 expression following hcIE deletion (Figures 5C,D). Bcl6 binding was augmented at BS4, BS5, and BS6 in intron 2 but not at CNS2 (BS7) in hcIE-KO $\mathrm{MPT}_{\mathrm{H}} 2$ cells compared with that in hcIE-WT background cells (Figure 5E), indicating that hcIE activity dampens Bcl6-mediated suppressor activity for intron 2 except at the CNS2 region.

\section{Bcl6 Suppresses Initial IL-4 Production in MPT Cells and $\mathrm{T}_{\mathrm{H}} 2$ Cell Differentiation}

Because IL-4 production by MPT cells plays an important role in $\mathrm{NAT}_{\mathrm{H}} 2$ cell differentiation (28), to address the effects of Bcl6 on MPT cell function, Bcl6-WT-naïve KJ1-26+ $\mathrm{CD}^{+}$ T cells were cocultured with KJ1-26- MPT cells from Bcl6-TG, $B c l 6-\mathrm{KO}$, or Bcl6-WT mice in the presence of soluble anti-CD3 and CD28 mAbs and irradiated $\mathrm{CD} 11 \mathrm{c}^{+} \mathrm{DCs}$ as the $\mathrm{T}_{\mathrm{H}} 0$ condition. Differentiation of IL-4-producing KJ1-26+ ${ }^{+} \mathrm{NAT}_{\mathrm{H}} 2$ cells varied inversely with Bcl6 levels in $\mathrm{KJ} 1-26^{-} \mathrm{MPT}$ cells, whereas IFN- $\gamma$-producing $\mathrm{NAT}_{\mathrm{H}} 1$ cells differentiated in the opposite direction (Figures 6A,B). Because MP cell-derived IFN- $\gamma$ may affect $\mathrm{NAT}_{\mathrm{H}} 2$ cell differentiation, we analyzed the $\mathrm{T}_{\mathrm{H}} 2$ skewing of naïve $\mathrm{CD}^{+} \mathrm{T}$ cells cocultured with MPT cells by excluding the effect of endogenous IFN $-\gamma$. Although $\mathrm{T}_{\mathrm{H}} 2$ skewing became prominent in the coculture in the presence of anti-IFN- $\gamma$ Abs regardless of the Bcl6 genotype, the skewing was still suppressed in the presence of Bcl6-TG MPT cells. Therefore, Bcl6 plays an important role in suppressing MPT cell function to skew naïve $C D 4^{+} \mathrm{T}$ cells toward the $\mathrm{T}_{\mathrm{H}} 2$ phenotype (Figures 6A,B). Furthermore, regardless of the Bcl6 genotype, intrinsic IL- 4 in MPT cells was involved in preserving the $\mathrm{T}_{\mathrm{H}} 2$ cell phenotype (Figures S5A,B in the Supplementary Material).

As CNS2-active MPT cells are essential for inducing $\mathrm{T}_{\mathrm{H}} 2$ responses following immunization in an allergic murine model (28), we examined Bcl6 function in the MPT cell-induced response during the development of allergic immunity in BALB/c $n u / n u$ mice undergoing adoptive transfer of Bcl6-WT-naïve $\mathrm{CD}^{+} \mathrm{T}$ cells $\left(\mathrm{KJ} 1-26^{+}\right)$and MPT cells $\left(\mathrm{KJ} 1-26^{-}\right)$from each respective $B c l 6$ genotype. Following OVA challenge in the mice, the numbers of all inflammatory cells, neutrophils, eosinophils (left), and $\mathrm{KJ} 1-26^{+} \mathrm{T}$ cells (right) in whole lung tissues were significantly increased, being inversely correlated with $\mathrm{Bcl} 6$ levels in the transferred MPT cells (Figures 7A,B). In BALF from the recipients, the $\mathrm{T}_{\mathrm{H}} 2$ cytokine concentrations of IL-4, IL-5, and IL-13, but not IFN- $\gamma$, were decreased after the last OVA challenge, with this effect being dependent on Bcl6 levels in the transferred MPT cells (Figure 7C). In KJ1-26+ T cells (naïvederived $\mathrm{T}_{\mathrm{H}}$ cells) from the spleens of recipients after the last OVA challenge, $\mathrm{T}_{\mathrm{H}} 2$ cytokine mRNA expression (Il4, Il5, and Il13) was decreased depending on Bcl6 levels in the transferred MPT cells (Figure 7D). OVA-specific IgE levels in the sera were increased, in accordance with increased cytokine production after the last challenge (Figure 7E). This finding indicates that Bcl6 suppressed the development of allergic inflammation by reducing MPT cell function to facilitate $\mathrm{NAT}_{\mathrm{H}} 2$ cell differentiation. 

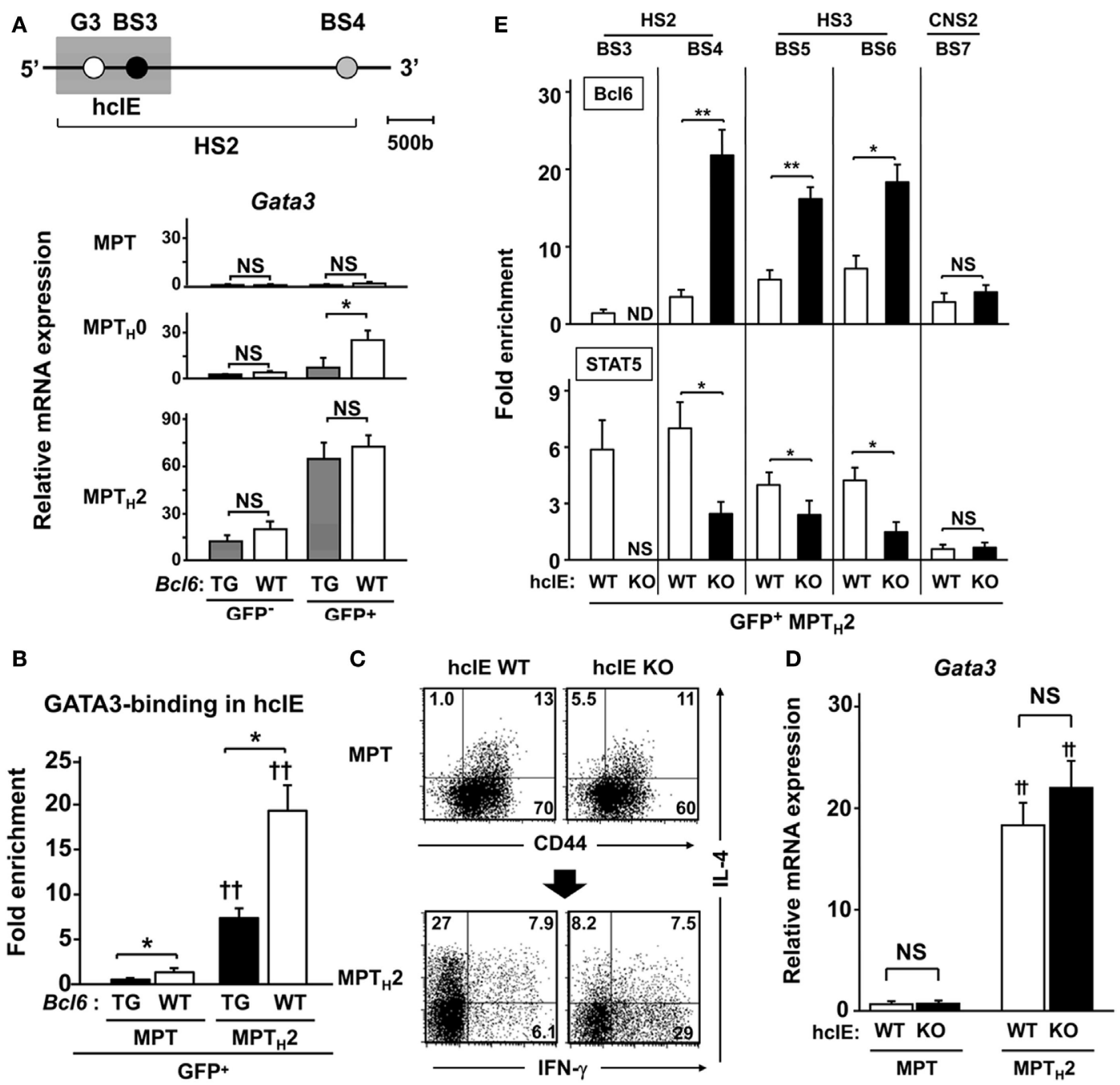

FIGURE 5 | Role of Bcl6 in hclE activity in MPTH2 cells. (A-D) KJ1-26+ cells among splenic MPT cells were cultured with ovalbumin peptides and antigen-presenting cells in vitro under $\mathrm{T}_{H} \mathrm{O}$ or $\mathrm{T}_{\mathrm{H}} 2$ conditions. [(A) top] Diagram of the HS2 region in //4 intron 2, indicating regulatory regions. The shaded square indicates the hclE region including the GATA3-binding site (G3) and BS3 within HS2. (A) Gata3 mRNA levels in GFP+ and GFP- MPT, MPTHO, and MPT 2 cells derived from Bc/6-TG and Bc/6-WT mice on a CNS2-GFP-TG background. (B) GATA3 binding to G3 analyzed by ChIP assays for GFP+ MPT and MPTH2 cells on a CNS2-GFP-TG background. (C,D) Analysis of splenic MPT cells or MPTH2 cells derived from hclE-KO or hclE-WT mice. (A) FACS analysis of intracellular cytokine populations of MPT cells by gating CD4+ ${ }^{+}$CD49b- T cells in the resting phase and MPT 2 cells restimulated with anti-CD3 monoclonal antibodies. The numbers in the corners represent the percentages among the gated T cells. (D) Gata3 mRNA levels were measured by GRT-PCR for MPT and MPTH2 cells derived from hclE-KO and hclE-WT mice. (E) Bcl6 levels and STAT5 binding to each BS were analyzed by ChIP assay for GFP+ MPTH2 cells from hclE-KO or hclE-WT mice on a CNS2-GFPTG background. All results are representative of three (A,B) or five (C-E) independent experiments with similar outcomes. Data are means \pm SEMs $(n=9-10)$. ${ }^{*} P<0.05$, comparison between two groups as indicated; ${ }^{t} P<0.05$, ${ }^{t} P<0.01$, compared with the MPT cells. Bcl6, B-cell lymphoma 6; BS, binding sequence; ChIP, chromatin immunoprecipitation; CNS, conserved noncoding sequence; FACS, fluorescence-activated cell sorting; hclE, highly conserved intron enhancer; HS, DNase hypersensitive site; KO, knockout; MPT cell, memory phenotype CD4+ ${ }^{+}$cell; MPT ${ }_{H} 2$ cell, MPT cell-derived $T_{H} 2$ cell; ND, not detected; NS, not significant; TG, transgenic; WT, wild-type.

\section{Bcl6 Attenuates the Synergistic Effect of MPT $_{\mathrm{H}} 2$ Cells and NAM-LT 2 Cells on Allergic Responses}

IL-4 levels were affected by Bcl6 in $\mathrm{NAMT}_{\mathrm{H}} 2$ cells, as previously reported (15). We focused on the functional difference in the spatiotemporal dynamics between $\mathrm{MPT}_{\mathrm{H}} 2$ and $\mathrm{NAMT}_{\mathrm{H}} 2$ cells. In the current study, NAM- $\mathrm{LT}_{\mathrm{H}} 2$ cells were analyzed as memory cells derived from naïve $\mathrm{CD}^{+} \mathrm{T}$ cells. In the resting phase,
$\mathrm{MPT}_{\mathrm{H}} 2$ cells constitutively express Il4, the expression of which is reduced in a Bcl6-dependent manner. Following $1 \mathrm{~h}$ of restimulation, Il4 expression in $\mathrm{MPT}_{\mathrm{H}} 2$ cells was increased to similar levels in each Bcl6 genotype, and the expression occurred earlier than that in Bcl6-WT-NAM-LT 2 cells. Il4 expression levels were decreased in most $\mathrm{MPT}_{\mathrm{H}} 2$ cells, but not $B c l 6-\mathrm{KO}$ cells, in a Bcl6-dependent manner at $8 \mathrm{~h}$ after restimulation (Figure 8A). In NAM-LT 2 cells, Il4 expression levels were low in the resting phase and increased after restimulation. The expression levels in 


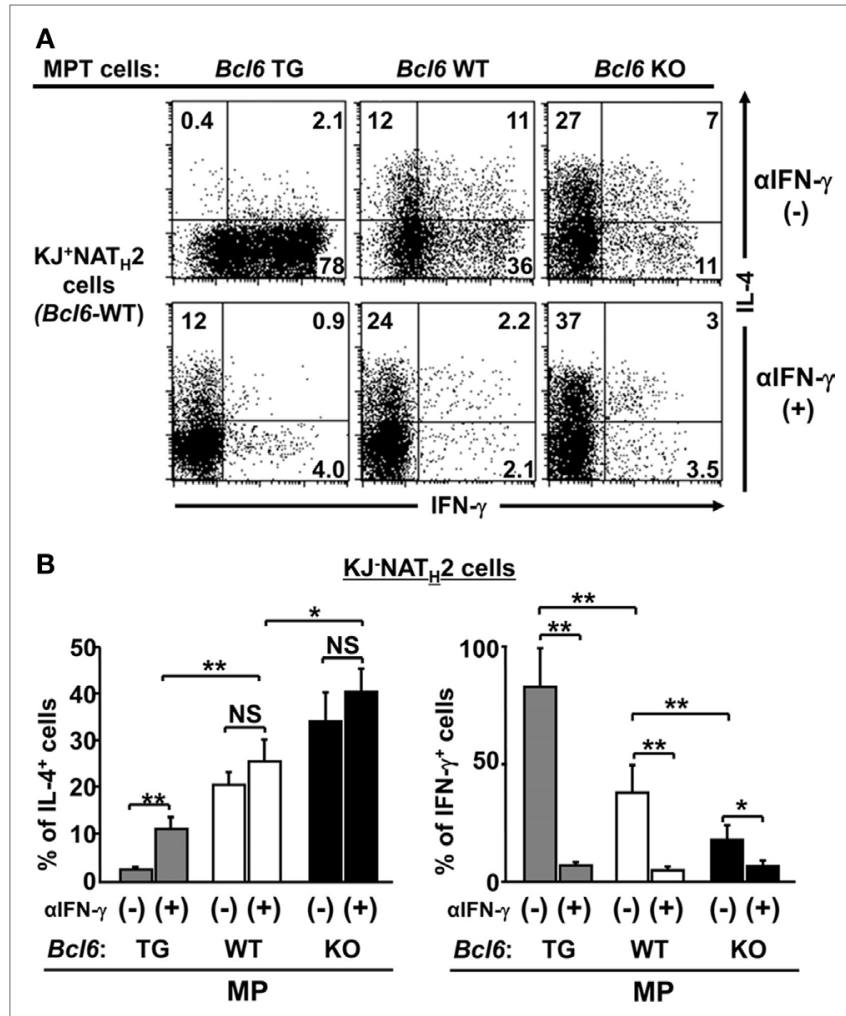

FIGURE 6 | Role of Bcl6 in initial IL-4 production by MPT cells to induce $\mathrm{NAT}_{\mathrm{H}} 2$ cells in vitro. $(\mathbf{A}, \mathbf{B}) \mathrm{Bc} / 6-\mathrm{WT} \mathrm{KJ} 1-26^{+}$naïve $\mathrm{CD}^{+} \mathrm{T}$ cells were cocultured with KJ1-26- MPT cells (Bc/6-TG, Bc/6-WT, or Bc/6-KO) in the presence of soluble anti-CD3 and CD28 mAbs and irradiated CD11 $\mathrm{C}^{+} \mathrm{DCs}$ as the $T_{H} 0$ condition with or without anti-IFN- $\gamma$ Abs. (A) FACS analysis of intracellular cytokines in each effector T cell type derived from $\mathrm{KJ}_{1-2{ }^{+}}$naïve $\mathrm{CD}^{+} \mathrm{T}$ cells are presented as a representative figure among three independent experiments after restimulation with anti-CD3 mAbs. Numbers in the corners denote the percentages of gated $\mathrm{KJ1} 1-26^{+} \mathrm{CD} 4^{+} \mathrm{T}$ cells. (B) Frequency of the populations of IL-4+ and IFN- $\gamma^{+} \mathrm{KJ} 1-26^{+} \mathrm{T}$ cells after reactivation. All results are representative of three independent experiments with similar outcomes. Data are presented as the mean \pm SEM $(n=8-9)$. ${ }^{\star} P<0.05$; ${ }^{\star \star} P<0.01$. Ab, antibody; Bcl6, B-cell lymphoma 6; DC, dendritic cell; KO, knockout; mAb, monoclonal antibody; MPT cell, memory phenotype $\mathrm{CD}^{+}{ }^{+} \mathrm{T}$ cell; $\mathrm{NAT}_{\mathrm{H}} 2$ cell; naïve $\mathrm{CD}^{+}{ }^{+} \mathrm{T}$ cell-derived $\mathrm{T}_{\mathrm{H}} 2$ cell; $\mathrm{TG}$, transgenic WT, wild-type.

Bcl6-WT-NAM-LT 2 cells were high, similar to those in Bcl6-KO $\mathrm{MPT}_{\mathrm{H}} 2$ cells at $8 \mathrm{~h}$ after restimulation (Figure $\mathbf{8 A}$ ). The protein levels of IL-4 and IL-5, but not of IL-13, were consistent with the Il4 expression pattern in each $\mathrm{T}_{\mathrm{H}} 2$ cell type (Figure S6 in Supplementary Material).

After adoptive transfer of each cell type $\left(\mathrm{MPT}_{\mathrm{H}} 2\right.$ cells or NAM$\mathrm{LT}_{\mathrm{H}} 2$ cells) with a DO11.10 genetic background into WT BALB/c $n u / n u$ mice, cell migration into lung tissues following OVA antigen challenge was determined and presented as percentages (Figure 8B) and absolute cell numbers (Figure 8C). Among Bcl6-WT cells, $\mathrm{MPT}_{\mathrm{H}} 2$ cells had greater migratory capability compared with NAM-LT 2 cells at $24 \mathrm{~h}$. The migration of $\mathrm{MPT}_{\mathrm{H}} 2$ cells decreased sequentially, whereas that of NAM- $\mathrm{LT}_{\mathrm{H}} 2$ cells increased at $48 \mathrm{~h}$. The migration of Bcl6-KO $\mathrm{MPT}_{\mathrm{H}} 2$ cells was further augmented compared with that of Bcl6-WT cells. Next, we assessed the role of $\mathrm{Bcl} 6$ in interactions between $\mathrm{MPT}_{\mathrm{H}} 2$ and Bcl6-WT-NAM-LT 2 cells during allergic responses. WT BALB/c mice were adoptively transferred with combinations of each type of KJ1-26+ $\mathrm{T}_{\mathrm{H}} 2$ cells and sequentially challenged with OVA (Figures 8D,E). When Bcl6-WT-NAM-LT 2 or Bcl6-WT MPT 2 cells were transferred, $\mathrm{T}_{\mathrm{H}} 2$ cytokine levels (IL-4, IL-5, and IL-13) in the BALF were similar among recipients, whereas Bcl6-KO $\mathrm{MPT}_{\mathrm{H}} 2$ cells induced a fourfold to sevenfold increase in $\mathrm{T}_{\mathrm{H}} 2$ cytokine levels. Combined transfer of Bcl6-WT-NAM-LT 2 and Bcl6-WT $\mathrm{MPT}_{\mathrm{H}} 2$ cells resulted in synergistic cytokine production, which was further augmented when $B c l 6-\mathrm{KO} \mathrm{MPT}_{\mathrm{H}} 2$ cells were transferred instead of Bcl6-WT MPT 2 cells (Figure 8D). The numbers of inflammatory cells, including eosinophils and lymphocytes, in the BALF (Figure 8E) were increased, in accordance with the increased production of cytokines, indicating that Bcl6 plays a critical role in regulating the functions of $\mathrm{MPT}_{\mathrm{H}} 2$ cells, which precede $\mathrm{NAMT}_{\mathrm{H}} 2$ cells in the development of local allergic pathology.

\section{IL-33 Reinforces IL-4 Production by MPT Cells}

Because we previously reported the effects of IL-33 on Bcl6mediated histone modification in memory $\mathrm{T}_{\mathrm{H}} 2$ cells to augment IL-4 production (15), we focused in this study on the effect of IL-33 on MPT cells. FACS analysis demonstrated no significant difference in the cell-surface expression of ST2, an IL-33R subunit on MPT cells, between Bcl6-TG and Bcl6-WT mice (Figures 9A,B). ST2 was preferentially expressed on $\mathrm{GFP}^{+} \mathrm{MPT}$ cells rather than $\mathrm{GFP}^{-}$cells. When MPT cells were cultured in the presence of IL-7 for 6 days followed by IL-33 administration (Figure 9C, top), the frequency (Figure 9C) and absolute number (Figure 9D) of IL- $4^{+} \mathrm{MPT}$ cells increased in a concentration-dependent manner at $8 \mathrm{~h}$ following the last IL-33 dose. The effect of IL-33 on IL-4 ${ }^{+}$MPT cells was significantly reduced in Bcl6-TG cells compared with that in WT cells (Figures 9C,D). Consistent with the priming effect of IL-33, we observed elevated levels of histone acetylation at BS sites in the Il4 locus with increased STAT5 histone association and decreased Bcl6 histone association. These effects of IL-33 on histone modification were attenuated in Bcl6-TG cells (Figure 9E).

\section{DISCUSSION}

The function of $\mathrm{Bcl} 6$ to regulated $\mathrm{T}_{\mathrm{H}} 2$ cytokine production is unclear. We found that Bcl6 negatively regulated IL-4 gene expression in MPT cells and their derived $\mathrm{MPT}_{\mathrm{H}} 2$ cells. Bcl6 inhibition significantly augmented IL-4 production by WT $\mathrm{MPT}_{\mathrm{H}} 2$ cells. Furthermore, IL-4 expression was reduced in T cell-specific Bcl6-TG MPT and Bcl6-TG MPT 2 cells, indicating a suppressive function of T cell-intrinsic Bcl6. CNS2 contains multiple putative binding sites for RBP-J, a critical modulator of notch signaling (34). CNS2 is regulated by notch signals to control initial IL-4 expression in MPT cells (28). We demonstrated that Bcl6 binds to CNS2, leading to suppression of its enhancer activity in $\mathrm{MPT}_{\mathrm{H}} 2$ cells. Bcl6 antagonizes notch-dependent transcription $(35,36)$. However, Rbpj deletion does not alter epigenetic markers on the 

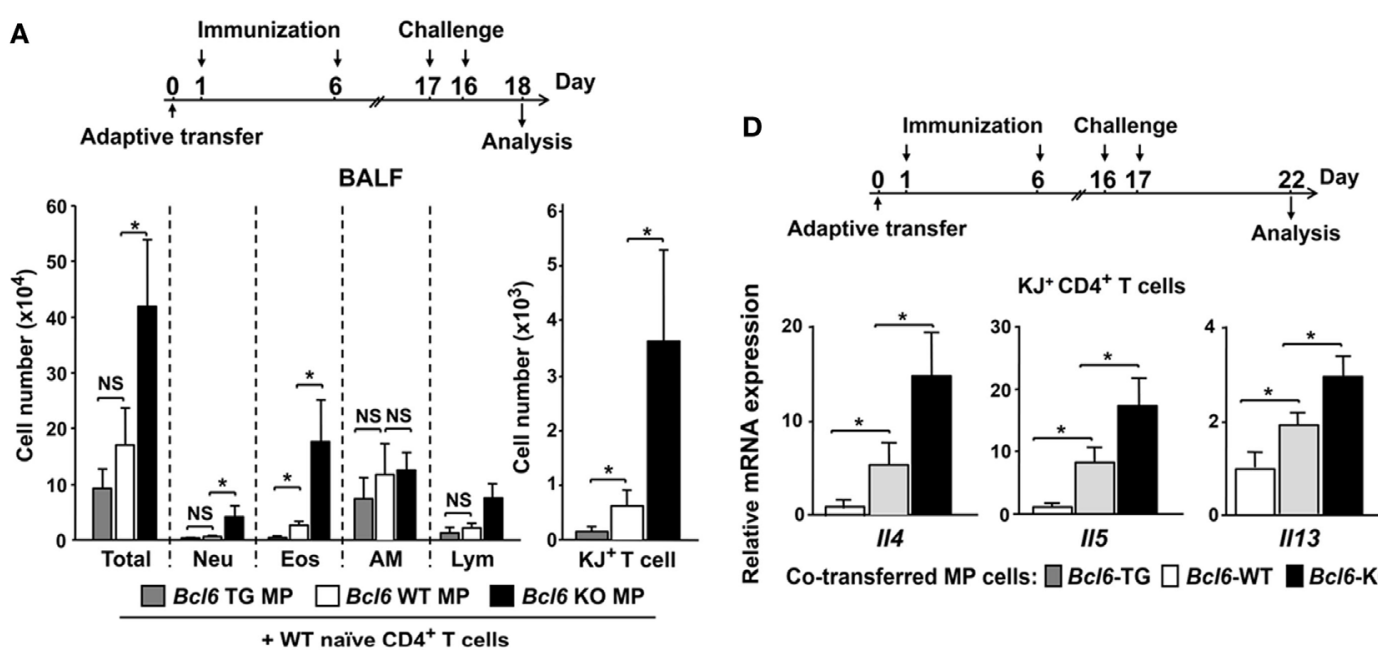

B
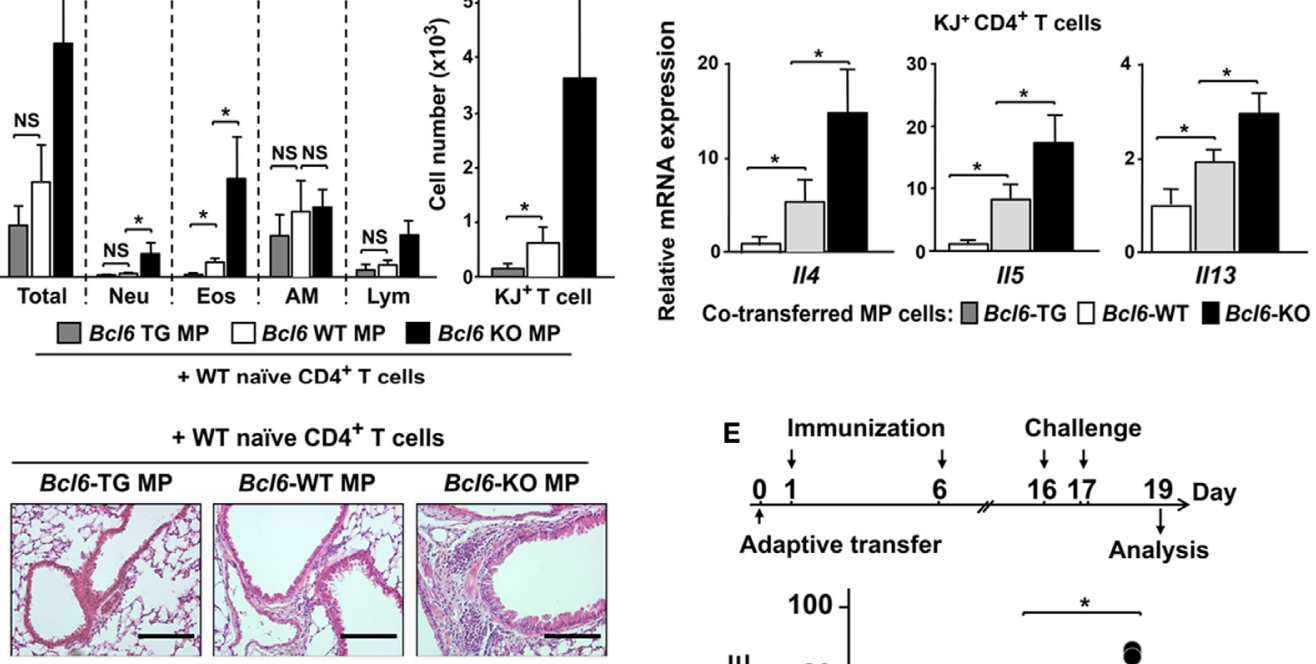

C
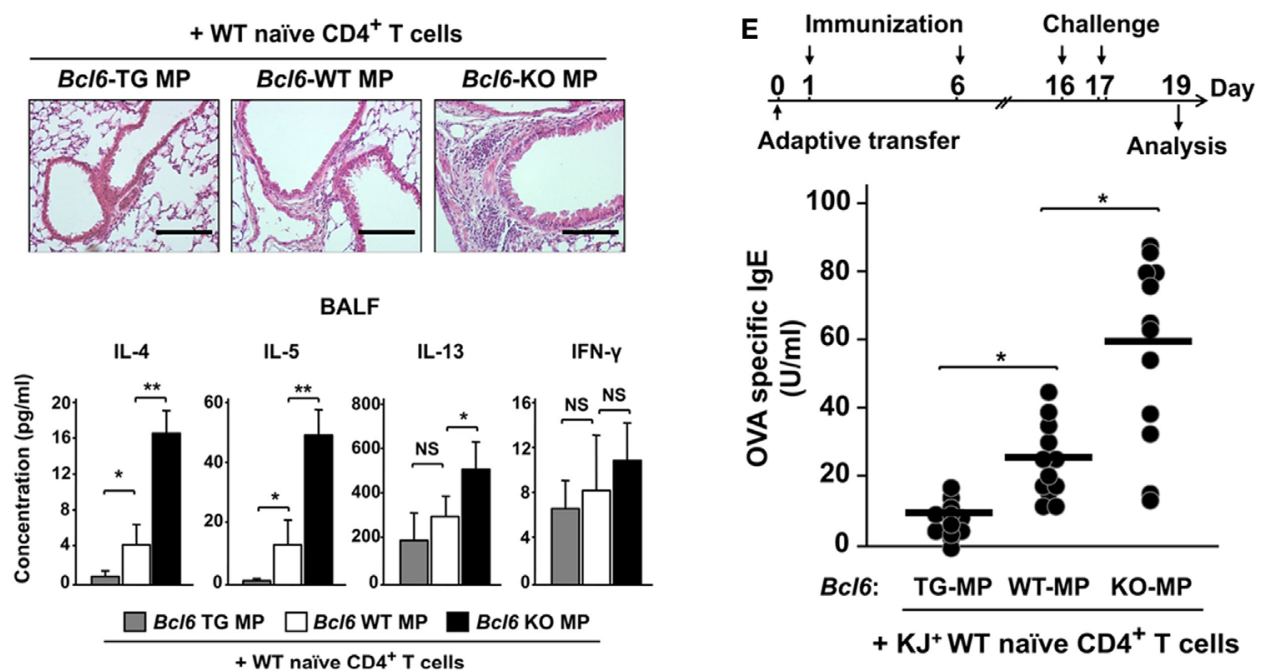

$+\mathrm{KJ}^{+} \mathrm{WT}$ naïve $\mathrm{CD4}^{+} \mathrm{T}$ cells

FIGURE 7 | Role of Bcl6-mediated MPT cell functions in NATH2 differentiation in an allergic murine model. [(A) top] Mixture of purified KJ1-26- MPT cells (Bc/6-WT or Bcl6-KO) and KJ1-26+ WT naïve CD4+ T cells were transferred into BALB/c nu/nu mice intravenously (day 0). These mice were immunized with alum-conjugated OVA and then intratracheally challenged with OVA. [(A) bottom] Absolute cell numbers of Neu, Eos, AM, and Lym in BALF, (B) hematoxylin and eosin-stained, formalin-fixed lung sections (magnification: 200x), and (C) $T_{H} 2$ cytokine levels in the BALF of recipient mice $48 \mathrm{~h}$ after the last OVA challenge. (D) Relative II4, II5, and $/ 113$ expression mRNA in splenic $\mathrm{KJ} 1-26^{+} \mathrm{T}$ cells restimulated with anti-CD3 monoclonal antibodies 5 days after the last challenge. (E) OVA-specific IgE antibody titers in sera from each recipient of Bc/6-WT NATH2 cells, plus MPTH2 cells transferred from Bc/6-TG, Bc/6-WT, or Bc/6-KO mice 2 days after the last challenge. All results are representative of four independent experiments with similar outcomes. Data are presented as the mean \pm SEM $(n=5-7)$. ${ }^{*} P<0.05$, ${ }^{\star \star} P<0.01$, comparison between two groups is indicated. AM, alveolar macrophages; BALF, bronchoalveolar lavage fluid; Bcl6, B-cell lymphoma 6; Eos, eosinophils; KJ+' KJ1-26-positive; KO, knockout; Lym, lymphocytes; MPT cell, memory phenotype CD4+ ${ }^{+}$cell; MPTH2 cell, MPT cell-derived TH2 cell; NATH2 cell; naiive CD4+ T cell-derived TH2 cell; Neu, neutrophils; NS, not significant; OVA, ovalbumin; TG, transgenic; WT, wild-type.

CNS2 site in $\mathrm{T}_{\mathrm{FH}}$ cells (29). Thus, to elucidate the positive regulatory mechanism of the activation of CNS2, a target of Bcl6 in MPT cells, further analysis is required.

GATA3 binding in the HS2 enhancer region is critical for $\operatorname{NAT}_{\mathrm{H}} 2(15,35)$ and $\mathrm{NAMT}_{\mathrm{H}} 2$ cells $(15)$. However, extremely low GATA3 expression might not be associated with IL-4 production in MPT cells. We demonstrated that GATA3-mediated hcIE activation is not essential for IL-4 production by MPT cells (Figures 5B-D). However, $\mathrm{MPT}_{\mathrm{H}} 2$ cell differentiation requires hcIE enhancer activity, which induces permissive histone modification of the Il4 locus by cooperating with STAT5 and GATA3 (37). Bcl6 directly bound to and interfered with hcIE function in $\mathrm{MPT}_{\mathrm{H}} 2$ cells. Accordingly, we suggest that diverse Bcl6 functions regulate IL-4 production in $\mathrm{MPT}_{\mathrm{H}} 2$ and MPT cells. The locus control region (LCR) at the Rad50 gene is also extremely important for $\mathrm{T}_{\mathrm{H}} 2$ cytokine expression. This region is considered to be involved in coordinating $\mathrm{T}_{\mathrm{H}} 2$ cytokine genes including IL-4. We previously reported the GATA3-binding site and Bcl6/STAT-binding sites in conserved regions $\left(\mathrm{T}_{\mathrm{H}}\right.$ 2LCR) in the Rad50 gene in another study (15). We also reported that Bcl6 binding in the LCR is augmented by disruption of hcIE in Il4, indicating that $\mathrm{Bcl} 6$-mediated $\mathrm{T}_{\mathrm{H}} 2 \mathrm{LCR}$ organizes $\mathrm{T}_{\mathrm{H}} 2$ cytokine gene including IL-4. Therefore, $\mathrm{T}_{\mathrm{H}} 2 \mathrm{LCR}$ may be implicated in Il4 regulation in CNS2-active MPT cells. To elucidate the role 


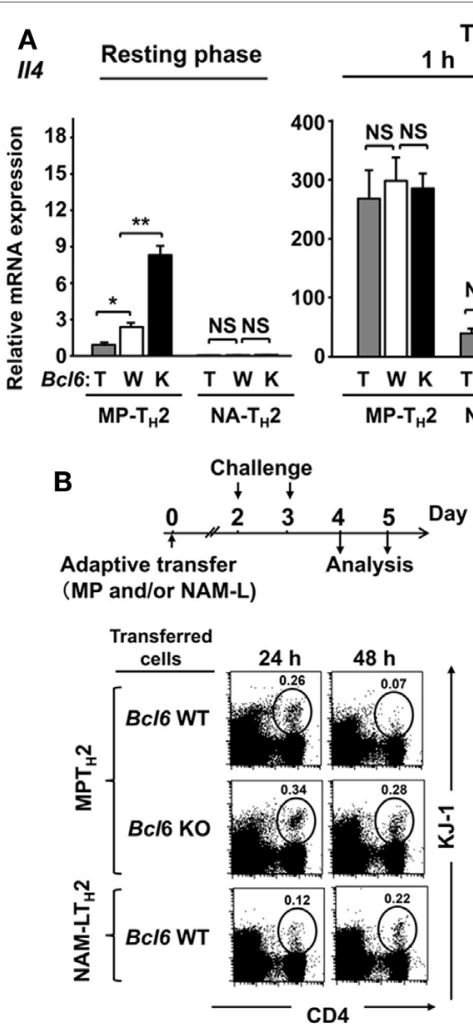

E

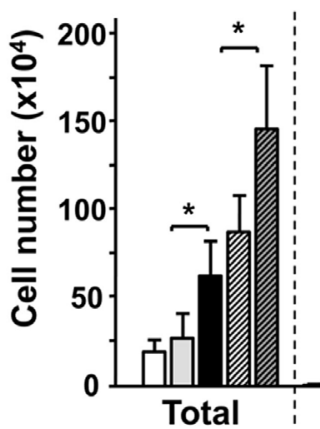

D

हิ
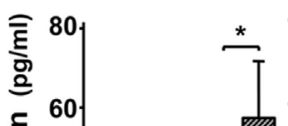

C

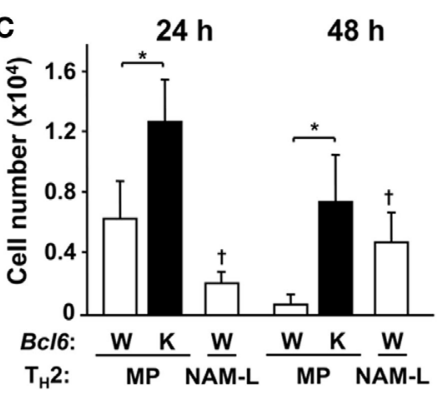

BALF

WT NAT $\mathrm{H}^{2} \square$ WT MPT $_{\mathrm{H}} 2 \square$ Bcl6 KO MPT $_{\mathrm{H}} 2$

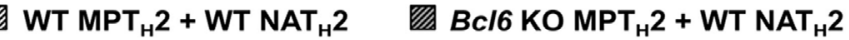

FIGURE 8 | Role of Bcl6 in interactions between MPTH2 and naïve NATH2 cells in allergy pathogenesis. (A-E) KJ1-26+ MPTH2 cells and NATH2 cells were differentiated from the spleens of Bc/6-TG (T), Bc/6-WT (W), and Bc/6-KO (K) mice in the presence of OVA peptides and antigen-presenting cells in TH2 conditions. (A) //4 mRNA levels in each $\mathrm{T}_{\mathrm{H}} 2$ cell type were measured by qRT-PCR at rest and at 1 and $8 \mathrm{~h}$ after restimulation with anti-CD3 monoclonal antibodies. (B-E) Bc/6-WT BALB/c nu/nu mice were administered KJ1-26+ MPT 2 cells $\left(3 \times 10^{7}\right)$, KJ1-26+ NATH2 cells $\left(3 \times 10^{7}\right)$, or combinations of MPTH2 (1.5 $\left.\times 10^{7}\right)$ and $\mathrm{NAT}_{\mathrm{H}} 2$ cells $\left(1.5 \times 10^{7}\right)$ via adoptive transfer (day 0). (B) Representative FACS data for donor cells in circles with their percentages among total CD4+ $\mathrm{T}^{\mathrm{B}}$ cells in whole lungs from recipients at 24 and $48 \mathrm{~h}$ after the last intratracheal OVA challenge. (C) Absolute numbers of KJ1-26+ cells in the lungs, (D) $\mathrm{T}_{\mathrm{H}} 2 \mathrm{Cytokine} \mathrm{levels,} \mathrm{and} \mathrm{(E)}$ cell types in the bronchoalveolar lavage fluid $48 \mathrm{~h}$ after the last challenge. All results are representative of four independent experiments with similar outcomes. Data are presented as the mean \pm SEM $(n=8-10)$. ${ }^{*} P<0.05,{ }^{*} P<0.01$, comparison between two groups is indicated $(\mathbf{A}, \mathbf{B}, \mathbf{D}, \mathbf{E}) ;{ }^{t} P<0.05$, compared with $\mathbf{M P T} 2$ cells. AM, alveolar macrophages; Bcl6, B-cell lymphoma 6; Eos, eosinophils; FACS, fluorescence-activated cell sorting; KO, knockout; Lym, lymphocytes; MPT cell, memory phenotype CD4+ T cell; MPT ${ }_{H} 2$ cell, MPT cell-derived $T_{H} 2$ cell; $N_{A} T_{H} 2$ cell; naïve CD4+ T cell-derived $T_{H} 2$ cell; Neu, neutrophils; NS, not significant; OVA, ovalbumin; TCR, T cell receptor; TG, transgenic; WT, wild-type.

of $\mathrm{T}_{\mathrm{H}} 2 \mathrm{LCR}$, further studies using region-deficient mice are required.

B-cell lymphoma 6 has various regulatory functions associated with cell viability and cytokine production, although the detailed molecular mechanisms have not been clarified. We observed that CNS2-active MPT cells contained high Bcl6 levels that declined following augmented IL-4 production under $\mathrm{T}_{\mathrm{H}} 2$ priming conditions. Intriguingly, in Bcl6-WT $\mathrm{MPT}_{\mathrm{H}} 2$ cells, 


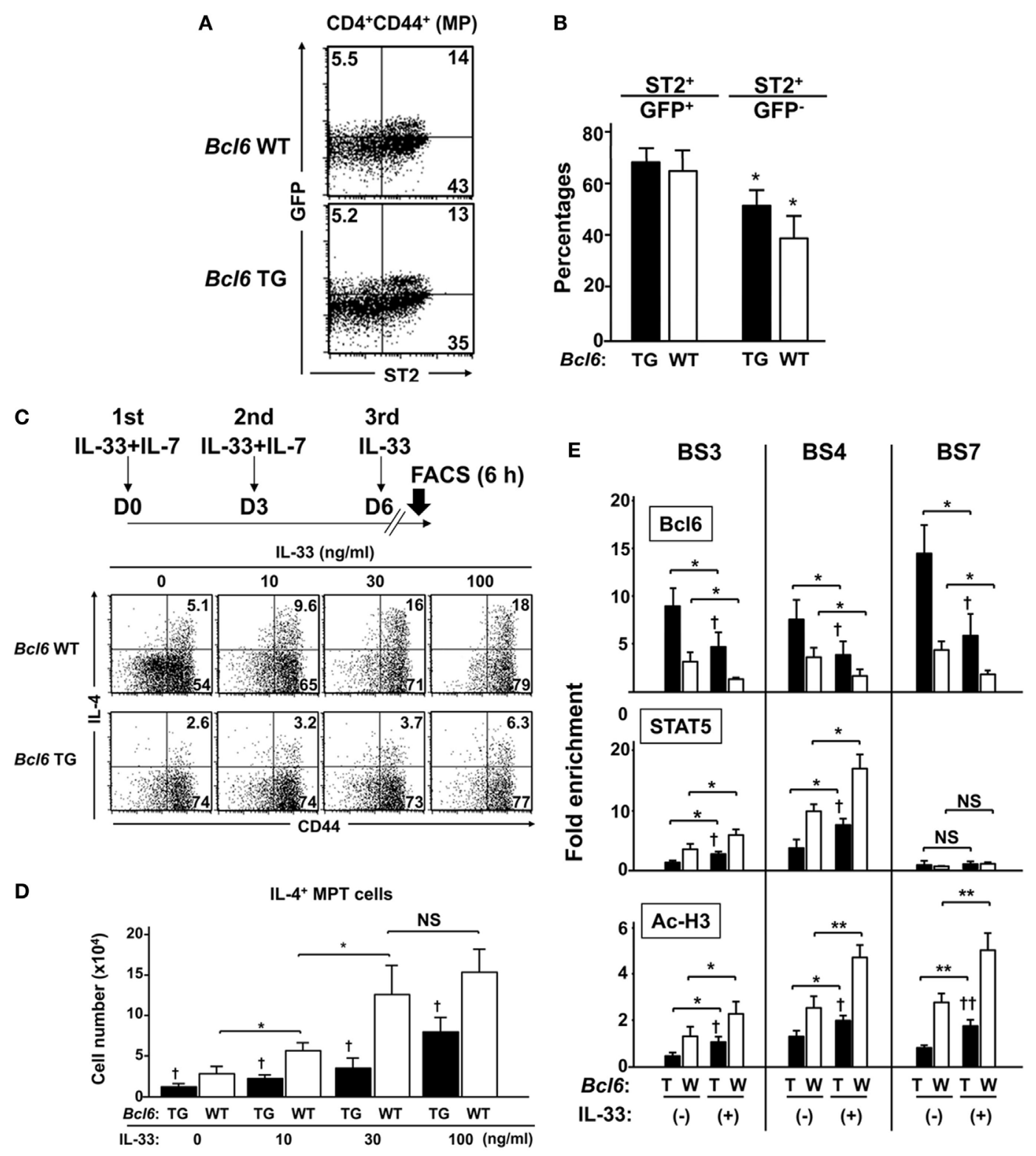

B

FIGURE 9 | IL-33 reinforces IL-4 production by MPT cells through functional competition against the suppressor activity of Bcl6. (A,B) FACS analysis of splenic CNS2-GFP-TG MPT cells from Bc/6-TG and Bc/6-WT mice at rest. (A) Data show the expression of GFP and ST2 gated cells among all CD4+ CD44+ cells (representative of six independent experiments). (B) Percentages of ST2+ cells among GFP+ and GFP- MPT cells. (C,D) IL-33 was added to the culture of MPT cells from Bc/6-TG and Bc/6-WT mice three times in the presence of IL-7. [(C) top] Six hours after the last IL-33 dose, MPT cells were analyzed for intracellular IL-4 levels. Numbers indicate the percentage of IL-4+ cells among all MPT cells. [(C) bottom] FACS analysis data are representative of four independent experiments.

(D) Absolute numbers of IL-4+ MPT cells $8 \mathrm{~h}$ after the last IL-33 dose. (E) ChIP analysis of Bcl6 and STAT5 binding and Ac-H3 at each BS in CNS2-GFP+ MPT cells from Bc/6-TG (T) and Bc/6-WT mice(W). Cells were primed with or without IL-33 three times in the presence of IL-7. Analysis was performed $8 \mathrm{~h}$ after the last IL-33 dose. All results are representative of three (A-D) or four (E) independent experiments with similar outcomes. Data are presented as the mean \pm SEM $(n=6-7)$. ${ }^{\star} P<0.05,{ }^{\star \star} P<0.01$, comparison between two groups is indicated; ${ }^{\mathrm{t} P}<0.05$, ${ }^{\mathrm{t}} \mathrm{P} P<0.01$, compared with WT. Ac-H3, acetylated histone H3; Bcl6, B-cell Iymphoma 6; BS, binding sequence; ChIP, chromatin immunoprecipitation; CNS, conserved noncoding sequence; FACS, fluorescence-activated cell sorting; GFP, green fluorescent protein; MPT cell, memory phenotype CD4+ T cell; TG, transgenic; WT, wild-type.

the CNS2-active population exhibited markedly lower Bcl6 levels and higher Il4 levels than the CNS2-inactive population. Greater Bcl6 mRNA levels in CNS2-active MPT cells than in the CNS2-inactive population in WT mice have been reported (29), whereas we observed slight differences in expression between these two populations. However, Bcl6 protein levels in CNS2-active Bcl6-WT MPT cells were inversely decreased relative to those in the CNS2-inactive MPT cells. Therefore, when pleiotropic Bcl6 effects are required in the same cellular environment, its function may be quantitatively controlled at transcriptional, translational, or post-transcriptional levels. 
We previously demonstrated that $\mathrm{T}_{\mathrm{H}} 2$ cytokine genes are negatively regulated by Bcl6 through chromatin remodeling and that interactions between Bcl6 and STAT5 are physiologically implicated in histone modulation and consequently cytokine production in $\mathrm{NAMT}_{\mathrm{H}} 2$ cells rather than $\mathrm{NAT}_{\mathrm{H}} 2$ cell differentiation (15). In a previous report, we advocated that STAT5 and GATA3 cooperate in permissive histone modification of the Il4 locus by binding to hcIE and that STAT5- and GATA3-mediated epigenetic activity of hcIE may be controlled by directly and/or indirectly preventing the $\mathrm{Bcl} 6$-mediated silencing. In addition, $\mathrm{Bcl} 6$ binding to BS4, BS5, and BS6 in the Il4 locus was augmented upon hcIE disruption in differentiating $\mathrm{T}_{\mathrm{H}} 2$ cells. Therefore, even in the presence of high levels of Bcl6, Bcl6-TG naïve $\mathrm{CD}^{+}{ }^{+} \mathrm{T}$ cells could differentiate into $\mathrm{T}_{\mathrm{H}} 2$ cells under the $\mathrm{T}_{\mathrm{H}} 2$ full commitment condition. Conversely, when naïve Bcl6-TG, Bcl6-WT, and Bcl6-KO CD4 ${ }^{+}$ T cells are stimulated under the $\mathrm{T}_{\mathrm{H}} 0$ condition, IL- 4 production by restimulated $\mathrm{CD}^{+} \mathrm{T}$ cells was reduced in a Bcl6 level-dependent manner. Therefore, we propose that the repressor activity of Bcl6 in the Il4 locus including hcIE and CNS2 can be determined in functional balance with transcriptional activators, such as GATA3, STATs, and RBP-J, in both $\mathrm{MPT}_{\mathrm{H}} 2$ and $\mathrm{NAT}_{\mathrm{H}} 2$ cells. Accordingly, both quantitative and qualitative Bcl6 functional modifications, such as reduced binding activity (15), may be implicated in the gene regulation of Il4. Notably, we observed that Bcl6 binding to the Il4 locus is higher in CNS2-GFP- Bcl6-TG MPT 2 cells than in $\mathrm{GFP}^{+} \mathrm{B}$ cl6-TG cells. Because enhancers can generally regulate transcription by interacting with enhancers or promoters via chromatin looping mechanisms, we propose that CNS2 may also stimulate Il4 transcription via physical interactions with hcIE, which may influence and organize Bcl6/STAT binding in hcIE. Therefore, Bcl6 binding to the Il4 locus may exceed STAT5 binding via Bcl6-mediated inhibition of CNS2 activity.

In earlier reports, we and other groups uncovered that Bcl6 has no significant intrinsic function in the differentiation of naïve CD4 ${ }^{+} \mathrm{T}$ cells into $\mathrm{T}_{\mathrm{H}} 1 / \mathrm{T}_{\mathrm{H}} 2$ cells in full commitment experiments in vitro. In later studies focusing on $\mathrm{T}_{\mathrm{FH}}$ cells, Bcl6 suppressed effector $\mathrm{T}$ cells, including $\mathrm{T}_{\mathrm{H}} 1, \mathrm{~T}_{\mathrm{H}} 2$, and $\mathrm{T}_{\mathrm{H}} 17$ cells, resulting in the induction of $\mathrm{T}_{\mathrm{FH}}$ cell differentiation. The current study indicated that Bcl 6 promotes IFN- $\gamma$ production via by inhibiting IL-4 production in activated naïve $\mathrm{CD} 4^{+} \mathrm{T}$ cells and MPT cells in some experimental settings, rather than inhibiting IL-4 production by promoting IFN- $\gamma$ production.

Contrarily, we previously reported that Bcl6 plays an important anti-apoptotic role in effector-derived memory precursor $\mathrm{CD}^{+}$ $\mathrm{T}$ cells, suggesting that $\mathrm{Bcl} 6$ is involved in long-term memory $\mathrm{T}$ cell survival $(17,30,38)$. We observed that the numbers of splenic MPT cells and, intriguingly, CNS2-active $\mathrm{GFP}^{+} \mathrm{MPT}$ cells were positively associated with intrinsic Bcl6 levels, whereas the MFI of GFP was reduced in Bcl6-TG cells. Recently, CNS2-active $\mathrm{GFP}^{+} \mathrm{CD}^{+} \mathrm{T}$ cells in secondary lymphoid tissues were found to have a high Bcl6 expression phenotype, similar to $\mathrm{T}_{\mathrm{FH}}$ cells (29). Bcl6 is a master regulatory factor for $\mathrm{T}_{\mathrm{FH}}$ cell differentiation. However, a substantial Bcl6-KO MPT cell population exists, and we suggested that CNS2-active MPT cells are not necessary as part of the $\mathrm{T}_{\mathrm{FH}}$ cell lineage. Although the molecular mechanism is unclear, Bcl6 may be implicated in, but not essential for, the development and/or maintenance of MPT and $\mathrm{MPT}_{\mathrm{H}} 2$ cells.
$\mathrm{NAMT}_{\mathrm{H}} 2$ cells have an important role in chronic allergic responses (15), although the relationship between $\mathrm{NAMT}_{\mathrm{H}} 2$ and $\mathrm{MPT}_{\mathrm{H}} 2$ cells is unclear. We observed that $\mathrm{T}_{\mathrm{H}} 2$ cytokine production peaked and declined earlier in $B c l 6-\mathrm{WT}-\mathrm{MPT}_{\mathrm{H}} 2$ cells than in WT-NAM-LT 2 cells. Moreover, the migratory function of $\mathrm{MPT}_{\mathrm{H}} 2$ cells was superior to that of NAM-LT 2 cells, albeit due to an unknown mechanism. Because CNS2 and Il4 are constitutively activated in $\mathrm{MPT}_{\mathrm{H}} 2$ cells but not in $\mathrm{NAMT}_{\mathrm{H}} 2$ cells (15), $\mathrm{MPT}_{\mathrm{H}} 2$ cells might influence $\mathrm{NAMT}_{\mathrm{H}} 2$ cell function in chronic allergy. Accordingly, $\mathrm{MPT}_{\mathrm{H}} 2$ cells organize $\mathrm{T}_{\mathrm{H}} 2$ immune responses directly and/or indirectly by regulating $\mathrm{NAMT}_{\mathrm{H}} 2$ cell function, resulting in allergy enhancement.

IL-4 production by CNS2-active MPT cells induced $\mathrm{T}_{\mathrm{H}} 2$ responses by inducing the differentiation of $\mathrm{NAT}_{\mathrm{H}} 2$ cells from naïve $\mathrm{CD}^{+} \mathrm{T}$ cells and their self-differentiation into $\mathrm{MPT}_{\mathrm{H}} 2$ cells following immunization (28). We confirmed initial IL-4 production from MPT cells in this study. Because CNS2-active MPT cells do not belong to the $\mathrm{T}_{\mathrm{FH}}$ cell lineage derived from naive $\mathrm{CD}^{+} \mathrm{T}$ cells (29) but they rather develop from selected thymocytes among those expressing other MHC class II markers (39), IL- $4^{+}$MPT cells might develop independently of naïve CD4 ${ }^{+}$ $\mathrm{T}$ cells during thymic differentiation. In that case, sequentially differentiated $\mathrm{MPT}_{\mathrm{H}} 2$ cells as well as MPT cells contribute to the early pathology of some allergies.

When considering the nature of Bcl6 in MPT and $\mathrm{MPT}_{\mathrm{H}} 2$ cells in pathologic conditions, we should determine whether Bcl6 expression can be modified without artificial gene manipulation at both protein and RNA levels. Recently, we reported that a $\mathrm{T}_{\mathrm{H}} 2$-promoting factor, namely, IL-33-mediated breakdown of Bcl6 in $\mathrm{NAMT}_{\mathrm{H}} 2$ cells, is likely involved in allergies (15) given the effect of IL-33 on both MPT and NAMT 2 cells. Therefore, the IL-33/Bcl6 axis might participate in allergy pathology via the regulation of Il4 in MPT cells to promote disease development in $\mathrm{MPT}_{\mathrm{H}} 2$ and $\mathrm{NAMT}_{\mathrm{H}} 2$ cells, contributing to the maintenance and exacerbation of disease pathology.

In summary, the current study provides evidence for a novel role of $\mathrm{Bcl} 6$ in the functional regulation of $\mathrm{MPT}$ and $\mathrm{MPT}_{\mathrm{H}} 2$ cells, implying interplay between $\mathrm{Bcl} 6$ and transcriptional activators to promote the production of relevant $\mathrm{T}_{\mathrm{H}} 2$ cytokines, particularly IL-4. Thus, $\mathrm{T}_{\mathrm{H}} 2$ cell-promoting factors that suppress Bcl6 function may represent crucial therapeutic targets for $\mathrm{T}_{\mathrm{H}} 2$ cell-mediated diseases.

\section{ETHICS STATEMENT}

This study was carried out in accordance with the recommendations of the Chiba University Resolution on Use of Animals in Research. The protocol was approved by the Institutional Animal Care and Use Committee at Chiba University School of Medicine. The mice were maintained under specific pathogen-free conditions in the animal center of Chiba University Graduate School of Medicine.

\section{AUTHOR CONTRIBUTIONS}

MA and TO jointly designed the experiments and directed the study and wrote the manuscript. MA, TO, YK, JI, TT, NT, 
HW-T, LF, AS, HH, and MH performed the experiments. MA, $\mathrm{TO}, \mathrm{MH}, \mathrm{YF}$, and $\mathrm{KK}$ analyzed the data and generated the figures. YF, KT, TT, and TF provided reagents and/or support for the analysis.

\section{ACKNOWLEDGMENTS}

The authors thank S. Satake for technical support and S. Nakamura for secretarial services. This work was supported in

\section{REFERENCES}

1. Kubo M. Innate and adaptive type 2 immunity in lung allergic inflammation. Immunol Rev (2017) 278:162-72. doi:10.1111/imr.12557

2. Hirose K, Iwata A, Tamachi T, Nakajima H. Allergic airway inflammation: key players beyond the Th2 cell pathway. Immunol Rev (2017) 278:145-61. doi:10.1111/imr.12540

3. Paul WE. What determines Th2 differentiation, in vitro and in vivo? Immunol Cell Biol (2010) 88:236-9. doi:10.1038/icb.2010.2

4. Zhou M, Ouyang W. The function role of GATA- 3 in $\mathrm{T}_{\mathrm{H}} 1$ and $\mathrm{T}_{\mathrm{H}} 2$ differentiation. Immunol Res (2003) 28:25-37. doi:10.1385/IR:28:1:25

5. Dent AL, Shaffer AL, Yu X, Allman D, Staudt LM. Control of inflammation, cytokine expression, and germinal center formation by BCL-6. Science (1997) 276:589-92. doi:10.1126/science.276.5312.589

6. Ye BH, Cattoretti G, Shen Q, Zhang J, Hawe N, de Waard R, et al. The BCL-6 proto-oncogene controls germinal-centre formation and Th2-type inflammation. Nat Genet (1997) 16:161-70. doi:10.1038/ng0697-161

7. Yoshida T, Fukuda T, Hatano M, Koseki H, Okabe S, Ishibashi K, et al. A role of Bcl6 in mature cardiac myocytes. Cardiovasc Res (1999) 42:670-9. doi:10.1016/S0008-6363(99)00007-3

8. Harris MB, Chang CC, Berton MT, Danial NN, Zhang J, Kuehner D, et al. Transcriptional repression of stat6-dependent interleukin-4-induced genes by BCL-6: specific regulation of $\mathrm{I} \varepsilon$ transcription and immunoglobulin E switching. Mol Cell Biol (1999) 19:7264-75. doi:10.1128/MCB.19. 10.7264

9. Hatzi K, Nance JP, Kroenke MA, Bothwell M, Haddad EK, Melnick A, et al. BCL6 orchestrates Tfh cell differentiation via multiple distinct mechanisms. J Exp Med (2015) 212:539-53. doi:10.1084/jem.20141380

10. Kawamata N, Miki T, Ohashi K, Suzuki K, Fukuda T, Hirosawa S, et al. Recognition DNA sequence of a novel putative transcription factor, BCL6. Biochem Biophys Res Commun (1994) 204:366-74. doi:10.1006/bbrc.1994. 2468

11. Arguni E, Arima M, Tsuruoka N, Sakamoto A, Hatano M, Tokuhisa T. JunD/ AP-1 and STAT3 are the major enhancer molecules for high Bcl6 expression in germinal center B cells. Int Immunol (2006) 18:1079-89. doi:10.1093/intimm/ dxl041

12. Liao W, Spolski R, Li P, Du N, West EE, Ren M, et al. Opposing actions of IL-2 and IL-21 on Th9 differentiation correlate with their differential regulation of BCL6 expression. Proc Natl Acad Sci U S A (2014) 111:3508-13. doi:10.1073/pnas.1301138111

13. Liu X, Lu H, Chen T, Nallaparaju KC, Yan X, Tanaka S, et al. Genome-wide analysis identifies Bcl6-controlled regulatory networks during $\mathrm{T}$ follicular helper cell differentiation. Cell Rep (2016) 14:1735-47. doi:10.1016/j.celrep. 2016.01.038

14. Arima M, Toyama H, Ichii H, Kojima S, Okada S, Hatano M, et al. A putative silencer element in the IL-5 gene recognized by Bcl6. J Immunol (2002) 169:829-36. doi:10.4049/jimmunol.169.2.829

15. Ogasawara T, Hatano M, Satake H, Ikari J, Taniguchi T, Tsuruoka N, et al. Development of chronic allergic responses by dampening Bcl6-mediated suppressor activity in memory T helper 2 cells. Proc Natl Acad Sci US A (2017) 114:E741-50. doi:10.1073/pnas.1613528114

16. Toney LM, Cattoretti G, Graf JA, Merghoub T, Pandolfi PP, Dalla-Favera R, et al. BCL-6 regulates chemokine gene transcription in macrophages. Nat Immunol (2000) 1:214-20. doi:10.1038/79749 part by Grants-in-Aid for Scientific Research (C) (JP17K10005: MA; JP24591460: MA) from the Japan Society for the Promotion of Science.

\section{SUPPLEMENTARY MATERIAL}

The Supplementary Material for this article can be found online at https://www.frontiersin.org/articles/10.3389/fimmu.2018.00750/ full\#supplementary-material.

17. Ichii H, Sakamoto A, Arima M, Hatano M, Kuroda Y, Tokuhisa T, et al. Bcl6 is essential for the generation of long-term memory CD4+ T cells. Int Immuno (2007) 19:427-33. doi:10.1093/intimm/dxm007

18. Nurieva RI, Chung Y, Martinez GJ, Yang XO, Tanaka S, Matskevitch TD, et al. Bcl6 mediates the development of T follicular helper cells. Science (2009) 325:1001-5. doi:10.1126/science.1176676

19. Johnston RJ, Poholek AC, DiToro D, Yusuf I, Eto D, Barnett B, et al. Bcl6 and Blimp-1 are reciprocal and antagonistic regulators of $\mathrm{T}$ follicular helper cell differentiation. Science (2009) 325:1006-10. doi:10.1126/science.1175870

20. Yu D, Rao S, Tsai LM, Lee SK, He Y, Sutcliffe EL, et al. The transcriptional repressor Bcl-6 directs T follicular helper cell lineage commitment. Immunity (2009) 31:457-68. doi:10.1016/j.immuni.2009.07.002

21. Vos Q, Jones LA, Kruisbeek AM. Mice deprived of exogenous antigenic stimulation develop a normal repertoire of functional T cells. J Immunol (1992) 149:1204-10.

22. Dobber R, Hertogh-Huijbregts A, Rozing J, Bottomly K, Nagelkerken L. The involvement of the intestinal microflora in the expansion of CD4+ T cells with a naïve phenotype in the periphery. Dev Immunol (1992) 2:141-50. doi:10.1155/ 1992/57057

23. Byrne JA, Stankovic AK, Cooper MD. A novel subpopulation of primed T cells in the human fetus. J Immunol (1994) 152:3098-106.

24. Tough DF, Sun S, Zhang X, Sprent J. Stimulation of memory T cells by cytokines. Vaccine (2000) 18:1642-8. doi:10.1016/S0264-410X(99)00500-9

25. Szabolcs P, Park KD, Reese M, Marti L, Broadwater G, Kurtzberg J. Coexistent naïve phenotype and higher cycling rate of cord blood $\mathrm{T}$ cells as compared to adult peripheral blood. Exp Hematol (2003) 31:708-14. doi:10.1016/ S0301-472X(03)00160-7

26. Huang T, Wei B, Velazquez P, Borneman J, Braun J. Commensal microbiota alter the abundance and TCR responsiveness of splenic naïve CD4+ T lymphocytes. Clin Immunol (2005) 117:221-30. doi:10.1016/j.clim.2005.09.012

27. Younes SA, Punkosdy G, Caucheteux S, Chen T, Grossman Z, Paul WE. Memory phenotype CD4 T cells undergoing rapid, nonburst-like, cytokinedriven proliferation can be distinguished from antigen-experienced memory cells. PLoS Biol (2011) 9:e1001171. doi:10.1371/journal.pbio.1001171

28. Tanaka S, Tsukada J, Suzuki W, Hayashi K, Tanigaki K, Tsuji M, et al. The interleukin-4 enhancer CNS-2 is regulated by notch signals and controls initial expression in NKT cells and memory-type CD4 T cells. Immunity (2006) 24:689-701. doi:10.1016/j.immuni.2006.04.009

29. Harada Y, Tanaka S, Motomura Y, Harada Y, Ohno S, Ohno S, et al. The 3 enhancer CNS2 is a critical regulator of interleukin-4-mediated humoral immunity in follicular helper T cells. Immunity (2012)36:188-200. doi:10.1016/ j.immuni.2012.02.002

30. Ichii H, Sakamoto A, Hatano M, Okada S, Toyama H, Taki S, et al. Role for Bcl-6 in the generation and maintenance of memory CD8+ T cells. Nat Immunol (2000) 3:558-63. doi:10.1038/ni802

31. Fukuda T, Yoshida T, Okada S, Hatano M, Miki T, Ishibashi K, et al. Disruption of the Bcl6 gene results in an impaired germinal center formation. J Exp Med (1997) 186:439-48. doi:10.1084/jem.186.3.439

32. Morita S, Kojima T, Kitamura T. Plat-E: an efficient and stable system for transient packaging of retroviruses. Gene Ther (2000) 7:1063-6. doi:10.1038/ sj.gt.3301206

33. Tanaka S, Motomura Y, Suzuki Y, Yagi R, Inoue H, Miyatake S, et al. The enhancer HS2 critically regulates GATA-3-mediated Il4 transcription in T(H)2 cells. Nat Immunol (2011) 12:77-85. doi:10.1038/ni.1966 
34. Amsen D, Blander JM, Lee GR, Tanigaki K, Honjo T, Flavell RA, et al. Instruction of distinct CD4 $\mathrm{T}$ helper cell fates by different notch ligands on antigen-presenting cells. Cell (2004) 117:515-26. doi:10.1016/S00928674(04)00451-9

35. Sakano D, Kato A, Parikh N, McKnight K, Terry D, Stefanovic B, et al. BCL6 canalizes Notch-dependent transcription, excluding mastermind-like1 from selected target genes during left-right patterning. Dev Cell (2010) 18:450-62. doi:10.1016/j.devcel.2009.12.023

36. Valls E, Lobry C, Geng H, Wang L, Cardenas M, Rivas M, et al. BCL6 antagonizes NOTCH2 to maintain survival of human follicular lymphoma cells. Cancer Discov (2017) 7:506-21. doi:10.1158/2159-8290.CD-16-1189

37. Zhu J, Min B, Hu-Li J, Watson CJ, Grinberg A, Wang Q, et al. Conditional deletion of Gata3 shows its essential function in $\mathrm{T}(\mathrm{H}) 1-\mathrm{T}(\mathrm{H}) 2$ responses. Nat Immunol (2004) 5:1157-65. doi:10.1038/ni1128

38. Ichii H, Sakamoto A, Kuroda Y, Tokuhisa T. Bcl6 acts as an amplifier for the generation and proliferative capacity of central memory CD8+ T cells. J Immunol (2004) 173:883-91. doi:10.4049/jimmunol.173.2.883
39. Sofi MH, Qiao Y, Ansel KM, Kubo M, Chang CH. Induction and maintenance of IL-4 expression are regulated differently by the $3^{\prime}$ enhancer in CD4 T cells. J Immunol (2011) 186:2792-9. doi:10.4049/jimmunol.1003353

Conflict of Interest Statement: The authors declare that the research was conducted in the absence of any commercial or financial relationships that could be construed as a potential conflict of interest.

Copyright (C) 2018 Ogasawara, Kohashi, Ikari, Taniguchi, Tsuruoka, WatanabeTakano, Fujimura, Sakamoto, Hatano, Hirata, Fukushima, Fukuda, Kurasawa, Tatsumi, Tokuhisa and Arima. This is an open-access article distributed under the terms of the Creative Commons Attribution License (CC BY). The use, distribution or reproduction in other forums is permitted, provided the original author(s) and the copyright owner are credited and that the original publication in this journal is cited, in accordance with accepted academic practice. No use, distribution or reproduction is permitted which does not comply with these terms. 